\title{
Kinon-metidi (I. dio): Reaktivni međuprodukti u kemiji fenola i njihova primjena u organskoj sintezi
}

\author{
Đ. Škalamera, ${ }^{*}$ T. Šumanovac Ramljak i A. Husak \\ Institut Ruđer Bošković, Bijenička cesta 54, 10000 Zagreb
}

\begin{abstract}
|| Sažetak
Kinon-metidi (QM, naziv po IUPAC-u: kinometani) su reaktivni međuprodukti koji zauzimaju vrlo značajno mjesto u organskoj kemiji. Njihova primjena u organskoj sintezi je veoma velika, što je dovelo do razvoja velikog broja metoda za njihovo generiranje. Korisni su i u stereoselektivnim reakcijama, čime im je otvoren put za primjenu u totalnoj sintezi, nerijetko struktura koje su već pokazale značajnu biološku aktivnost. Ovim pregledom dan je uvid u metode sintetskog (termičkog) generiranja QM-a te njihovu primjenu u organskoj sintezi, s osvrtom na biološka svojstva samih QM-a ili produkata koji se iz njih dobivaju u sintezi.
\end{abstract}

\| Ključne riječi

Kinon-metidi, derivati fenola, termičko generiranje kinon-metida, kinon-metidi u organskoj sintezi, antiproliferativna aktivnost

\section{Uvod}

Kinon-metidi** (engl. quinone methides, QM, naziv po IUsto pojavljuju u kemiji i fotokemiji fenola te njima srodnih spojeva. ${ }^{1}$ Pretpostavlja se da sudjeluju kao međuprodukti u biotransformacijama lignina te kao vrlo važni reagensi npr. antibiotika mitomicina $\mathrm{C}^{3}$ i daunokarmicina. ${ }^{4}$ Pojavljuju se također i u mehanizmima biotransformacija vitamina E i K.5,6,7 Polarna priroda QM-a čini ih vrlo reaktivnima, pa reagiraju i s elektrofilima i s nukleofilima, što kao posljedicu ima da su oni kratkoživuće vrste s vremenima života tipično od $<1$ ns do nekoliko sekundi ili minuta., ${ }^{1,8}$ Izrazita reaktivnost s nukleofilima čini ih primjenjivim u biološkim sustavima gdje mogu alkilirati biološki važne nukleofile: alkohole, ${ }^{9}$ tiole, ${ }^{10,11}$ nukleinske kiseline, ${ }^{12}$ proteine ${ }^{11 b, 13}$ i fosfodiestere. ${ }^{14} \mathrm{QM}$ se mogu generirati reakcijama u osnovnom stanju (termički), ${ }^{15}$ kao i fotokemijskim metodama. ${ }^{1}$ Osim u tu svrhu, u literaturi su opisane brojne druge primjene QM-a, npr. kao antimalarika, ${ }^{16}$ inhibitora mitohondrijske respiracije, ${ }^{17}$ inhibitora glukuronidaze ${ }^{18}$ te za detekciju fiziološki važnih tiola. ${ }^{19}$ Važna primjena tih reaktivnih međuprodukata zauzima svoje mjesto u organskoj sintezi. ${ }^{20} \mathrm{U}$ ovom radu bit će više riječi o strukturi i reaktivnosti QM-a i njihovoj primjeni u organskoj sintezi tada kad su generirani reakcijama u osnovnom stanju (termički). PAC-u: kinometani) su reaktivni međuprodukti koji se čeu mehanizmu djelovanja mnogih antitumorskih lijekova, ${ }^{2}$

\section{Općenito o kinon-metidima}

\subsection{Struktura kinon-metida}

Osnovni (roditeljski) o- $\mathbf{1}$ i p- $\mathbf{3}$ kinon-metidi sastoje se od cikloheksadienskog skeleta na kojem su vezane metilenska i karbonilna skupina koje su međusobno u konjugaciji, dok se $m$ - supstituirani analog 2 može prikazati kao rezonancijski hibrid zwitteriona i biradikala (slika 1).

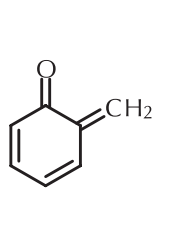

$o-\mathrm{QM}$

1

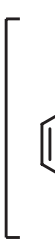<smiles>[O-]c1cccc(O)c1</smiles>
$m-\mathrm{QM}$<smiles>CCc1cccc(O)c1</smiles><smiles>C=C1C=CC(=O)C=C1</smiles>

$p-\mathrm{QM}$

3
Slika 1 - Strukture roditeljskih QM

Fig. 1 - Structures of parent QMs

Strukturno su srodni $p$-kinonu (4) i $p$-kinon-dimetidu (ksililenu) (5) (slika 2).<smiles>O=C1C=CC(=O)C=C1</smiles>

4<smiles>C=c1ccc(=C)cc1</smiles>

5 pako IUPAC više ne preporučuje upotrebu naziva kinon-metid, već pre-
poruce kinometan, autori ovog pregleda odlučili su zadržati stari naziv kinon-metid. Razlog tome je ponajprije usklađenost ovog članka sa svom ostalom relevantnom i recentnom literaturom o kinon-metidima, koja se koristi upravo tim nazivom.
Slika 2 - Strukture $p$-kinona (4) i $p$-ksililena (5)

Fig. 2 - Structures of $p$-quinone (4) and $p$-xylylene (5) 
Osim osnovnih (roditeljskih) QM-a 1-3, u literaturi je uobičajeno kinon-metidima nazivati i sve ostale spojeve koji u svojoj strukturi sadrže metilensku i karbonilnu skupinu u vinilognom položaju. Tako se kinon-metidima nazivaju i derivati srodni m-QM-u 2, uobičajeni kod spojeva kod kojih zbog nemogućnosti konjugacije između metilenske skupine i kisika odgovarajući QM ima zwitterionski ili biradikalski karakter. Primjeri za navedene slučajeve prikazani su slikom 3.<smiles>COc1cccc2c1C(=O)c1c(O)c3c(c(O)c1=C2O)C[C@@](O)(C(C)=O)CC=3</smiles>

6

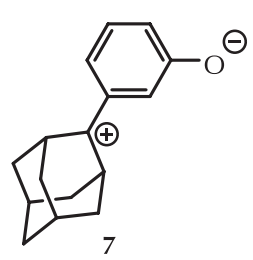

Slika 3 - Primjer neutralnog $\mathbf{6}^{2 \mathrm{a}}$ i zwitterionskog $7^{21} \mathrm{QM}-\mathrm{a}$ Fig. 3 - Example of neutral $6^{2 a}$ and zwitterionic $7^{21} \mathrm{QM}$

\subsection{Svojstva i kemijska reaktivnost kinon-metida}

QM su reaktivne kratkoživuće vrste, vremena života tipično od $<1$ ns pa do nekoliko minuta, te je stoga za njihovo proučavanje potrebno primjenjivati tehnike tranzijentne spektroskopije, primjerice lasersku pulsnu fotolizu (LFP, od engl. laser flash photolysis). QM reagiraju s elektrofilima preko kisikova atoma, na način koji je tipičan za fenolate, a s nukleofilima reagiraju na metilenskom položaju pri čemu nastaju produkti Michaelove adicije 10 (shema 1). Kako su QM znatno reaktivniji od običnih enona kakvi su npr. $\alpha, \beta$-nezasi eni ketoni, oni mogu reagirati i u [4+2] cikloadicijskim reakcijama (Diels-Alder) s dienofilima bogatim elektronima daju i kao produkte derivate kromana 9 (shema 1).

Rearomatizacija koja se događa u reakciji adicije ujedno je i pokretačka sila navedenih reakcija. Supstituenti na QM znatno utječu na brzinu reakcija, te tako mogu utjecati na duljinu vremena života QM-a. ${ }^{22}$ Obično su QM sami po sebi elektronski siromašni, pa će zbog toga elek-

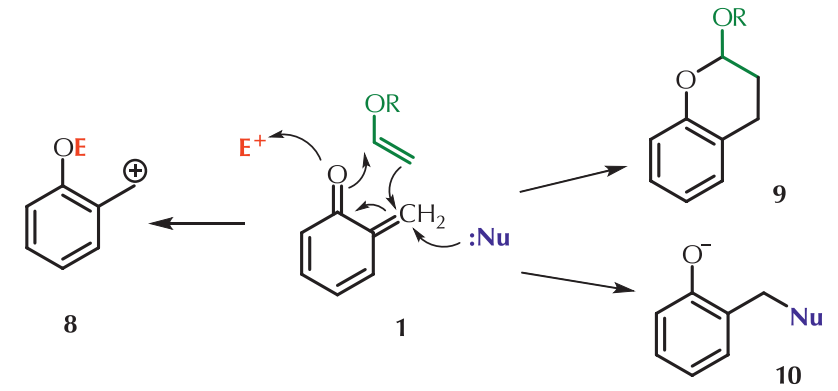

Shema 1 - Reakcije tipične za QM

Scheme 1 - Typical reactions of QMs

tron-odvlačeće skupine djelovati destabilizirajuće, dok će elektron-donirajuće djelovati stabilizirajuće. To je možda najbolje uočljivo na primjeru studije koju su proveli Rokita i Freccero sa svojim suradnicima, gdje su QM generirali iz kvaternih amonijevih soli 11a-f (shema 2) te određivali njegove brzine reakcija s $\mathrm{O}, \mathrm{N}$ i $\mathrm{S}$ nukleofilima (tablica 1$){ }^{23}$ Pokazali su da, kad je QM supstituiran elektron-odvlačecom nitro-skupinom, brzina reakcije s nukleofilima biva znatno veća nego u slučaju supstitucije elektron-donirajućom metoksi-skupinom.

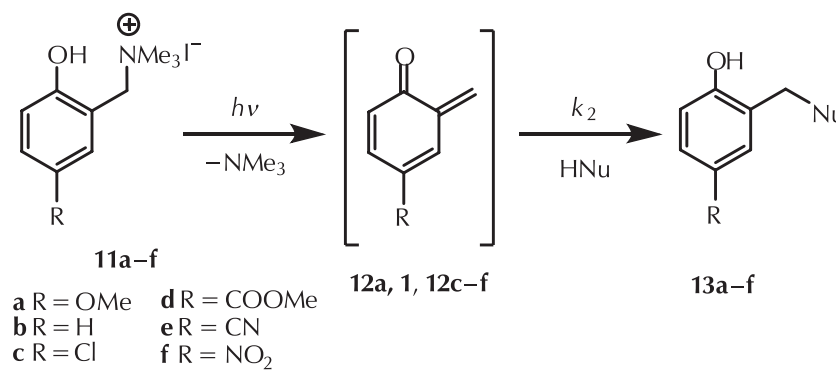

Shema 2 - Fotokemijsko generiranje QM-a iz različito supstituiranih prekursora $\mathbf{1 1}$

Scheme 2 - Photochemical generation of QM from differently substituted precursors 11

Tablica 1 - Svojstva QM-a generiranih iz derivata 11a-f i konstante brzina reakcije s nukleofilima

Table 1 - Properties of QMs generated from derivatives $\mathbf{1 1 a}-\mathbf{f}$ and rate constants for the reactions with nucleophiles

\begin{tabular}{c|c|c|c|c|cc|c}
\hline $\begin{array}{c}\text { Kvaterna amonijeva sol } \\
\text { Quaternary ammonium salt }\end{array}$ & $\mathrm{R}$ & $\mathrm{QM}$ & $\frac{\lambda_{\max }}{\mathrm{nm}}$ & $\frac{k_{2}\left(\mathrm{H}_{2} \mathrm{O}\right)}{\mathrm{mol}^{-1} \mathrm{dm}^{3} \mathrm{~s}^{-1}}$ & $\frac{k_{2}(\text { morfolin })^{\mathrm{a}}}{10^{-5} \mathrm{~mol}^{-1} \mathrm{dm}^{3} \mathrm{~s}^{-1}}$ & $\frac{k_{2}\left(\mathrm{R}^{\prime} \mathrm{SH}\right)}{10^{-5} \mathrm{~mol}^{-1} \mathrm{dm}^{3} \mathrm{~s}^{-1}}$ \\
\hline $\mathbf{1 1 a}$ & $\mathrm{OMe}$ & $\mathbf{1 2 a}$ & 410 & 1,9 & 5,5 & 0,40 \\
$\mathbf{1 1 b}$ & $\mathrm{H}$ & $\mathbf{1}$ & 400 & $7,8^{\mathrm{c}}$ & 23 & 1,9 \\
$\mathbf{1 1 c}$ & $\mathrm{Cl}$ & $\mathbf{1 2 c}$ & 400 & 22,8 & 36 & 5,4 \\
$\mathbf{1 1 d}$ & $\mathrm{COOMe}$ & $\mathbf{1 2 d}$ & 420 & 363 & 160 & 59 \\
$\mathbf{1 1 e}$ & $\mathrm{CN}$ & $\mathbf{1 2 e}$ & 415 & 1999 & 505 & $b$ \\
$\mathbf{1 1 f}$ & $\mathrm{NO}_{2}$ & $\mathbf{1 2 f}$ & 435 & 25400 & $b$ & $b$ \\
\hline
\end{tabular}

a pH je održavan na 9,0 s $\mathrm{Na}_{2} \mathrm{CO}_{3}$.

$\mathrm{pH}$ was maintained at 9.0 with $\mathrm{Na}_{2} \mathrm{CO}_{3}$.

b Tranzijentna apsorpcija QM-a 12f je u prisustvu morfolina i tiola potpuno ugašena.

Autori kao moguće objašnjenje navode prijenos elektrona s nukleofila na QM.

Transient absorption of QM $12 \mathrm{f}$ was completely quenched in the presence of morpholine and thiols.

A plausibile explanation is the electron transfer from the nucleophile to the QM.

${ }^{\mathrm{C}} \mathrm{U}$ radu Kresgea $i$ sur. ${ }^{23 \mathrm{~b}}$ navedena je konstanta brzine reakcije QM-a $1 \mathrm{~s} \mathrm{H}_{2} \mathrm{O}$ pseudoprvog reda koja iznosi $2,6 \cdot 10^{2} \mathrm{~s}^{-1}$.

The work of Kresge et al. ${ }^{23 \mathrm{~b}}$, states a pseudo-first order rate constant for the reaction of QM 1 with $\mathrm{H}_{2} \mathrm{O}$ with the value of $2.6 \cdot 10^{2} \mathrm{~s}^{-1}$. 


\subsection{Dokaz postojanja kinon-metida kao međuprodukata u termičkim reakcijama}

Kako su QM samo tranzijentne vrste, njihova struktura je pretpostavljena na temelju logičnog slijeda u mehanizmu kemijske reakcije, ali bez pravog dokaza nemoguće je tvrditi da oni kao takvi postoje. Međutim postoje indirektni dokazi o njihovu postojanju, dobiveni potvrdom strukture produkata dimerizacije, trimerizacije, intramolekulskih [4+2] cikloadicija, kao i reakcije QM-a s nukleofilima. Godine 1907. Fries je bio prvi koji je nastanak dimera i trimera u reakciji pripisao o-QM-u kao međuproduktu. ${ }^{24}$ lako navedeni dokazi dovode do zaključka da je (jedino) logično objašnjenje mehanizma tih reakcija postojanje QM-a kao međuprodukata, takvi dokazi su neizravni, posredni. Pravi dokaz strukture kinon-metida došao je tek 1959. godine, kad je Gardner uspio izolirati i spektroskopski dokazati strukturu roditeljskog o-QM-a 1 nastalog pirolizom o-metoksimetilfenola 14 (shema 3 ). ${ }^{25}$

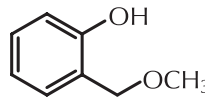

14

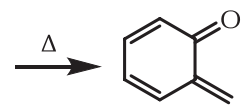

1
Shema 3 - Piroliza o-metoksimetilfenola

Scheme 3 - Pyrolysis of o-methoxymethylphenol<smiles>[R]C([R])=C1C=CC([TeH2+])=CC1=O</smiles>

15 a $R^{1}=R^{2}=H$

$15 \mathbf{b} \mathrm{R}^{1}=\mathrm{H}, \mathrm{R}^{2}=\mathrm{CH}_{3}$

$15 \mathrm{c} \mathrm{R} \mathrm{R}^{1}=\mathrm{CH}_{3}, \mathrm{R}^{2}=\mathrm{H}$

15d R $\mathrm{R}^{1}=\mathrm{CH}_{3}, \mathrm{R}^{2}=\mathrm{CH}\left(\mathrm{CH}_{3}\right)_{2}$<smiles>[R]C([R])=C1C=CC([R10]#[CH2+])=CC1=O</smiles>

16a $\mathrm{R}=\mathrm{H}$

$16 \mathbf{b} \mathrm{R}=\mathrm{CH}_{3}$

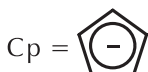

Slika 4 -Kompleksi iridija i rodija s različito supstituiranim o-QM-om

Fig. 4 -Complexes of iridium and rhodium with differently substituted $\mathrm{o}-\mathrm{QMS}$

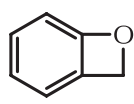

17

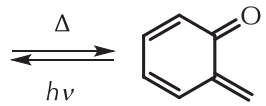

1
Shema 4 - Izomerizacija QM i BO

Scheme 4 - Isomerisation of QM and $\mathrm{BO}$
Kasnije je uslijedio velik broj pokušaja sinteze stabilnih QM-a, u kojima su za stabilizaciju na osnovnu strukturu QM-a bile pridodane elektron-donirajuće skupine ili heteroatom. Pokazano je da se QM-i mogu učiniti stabilnijima ako se na osnovnu strukturu veže neka velika skupina, npr. t-butil. Takav pristup je Dyallu i sur. omogućio pripravu većeg broja stabilnih QM-a, koje su potom studirali UV-om i NMR-om. ${ }^{26}$

Još jedan vrlo uspješan pokušaj priprave stabilnih QM-a je rad Amourija i sur. ${ }^{27}$ Oni su roditeljski o-QM 1 stabilizirali stvaranjem organometalnih $\pi$-kompleksa s osmijem, iridijem (15a-d) i rodijem (16a-b), u kojima o-QM ima ulogu $\eta^{4}$-donora (slika 4). QM je unutar takvog kompleksa znatno stabilniji, pa su autori uspjeli pripraviti monokristal i riješiti njegovu kristalnu i molekulsku strukturu metodom rendgenske difrakcije.

\subsection{Benzokseti - vezni izomeri kinon-metida}

Benzokseti (BO, 17) su vezni izomeri QM-a, inače heterociklički analozi benzociklobutena. To su napete molekule, što omogućava lako termičko ili fotokemijsko otvaranje prstena i nastanak stabilnijeg o-kinoidnog izomera 1 (shema 4). Takva izomerizacija između benzenoidne forme $\mathbf{1 7}$ te $o$-QM strukture 1 temelj je primjene benzokseta u sintezi. ${ }^{28}$
Jedan od zanimljivih primjera primjene međuprodukata BO u sintezi prikazan je shemom 5. Iz spoja 18 može se nakon eliminacije generirati reaktivni benzinski međuprodukt 19, koji potom u cikloadicijskoj reakciji [2+2] reagira s N,N-dialkilformamidima ili N,N-dialkilacetamidima dajući benzoksetne derivate $\mathbf{2 0}$ koji su u ravnoteži s odgovarajućim o-kinon-metidnim derivatima 21. Derivati 21 potom reagiraju s raznim nukleofilima dajući produkte prikazane shemom $5 .^{28}$

\subsection{Kinon-metidi prisutni u prirodi}

Kako se QM često javljaju u mehanizmima reakcija kod fenola i srodnih spojeva, koji su prisutni u prirodnim sustavima, može se očekivati da QM i u nekim od prirodnih sustava imaju ulogu međuprodukata. Smatra se da igraju vrlo važnu ulogu pri lignifikaciji (nastanak polimera lignina) u drvetu, kao sekundarni stanični zid u svim biljkama, ${ }^{1}$ te u nekim vrstama algi. ${ }^{29}$ Mehanizam biosinteze lignina uključuje polimerizaciju glikoziliranih monolignola koji potječu iz aminokiseline fenilalanina. Glikoziliranjem se postiže povećanje topljivosti i smanjenje toksičnosti. Polimerizacija je katalizirana oksidativnim enzimima i odvija se radikalskim mehanizmom koji uključuje QM. ${ }^{1}$ Tri vrlo uobičajena monolignola iz kojih kreće biosinteza lignina prikazana su na slici 5. Shemom 6 prikazan je skraćeni put biosinteze lignina preko međuprodukata QM-a. 


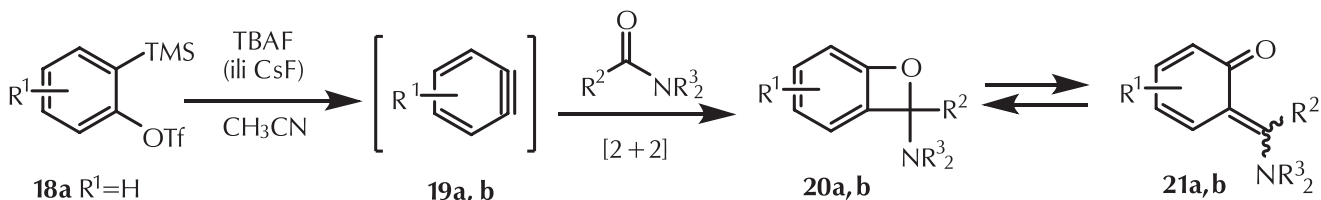

18a $\mathrm{R}^{1}=\mathrm{H}$

$19 a, b$

$20 \mathrm{a}, \mathrm{b}$

21a,b $\mathrm{NR}_{2}^{3}$

$18 \mathrm{bR}^{1}=\mathrm{OCH}_{3}$

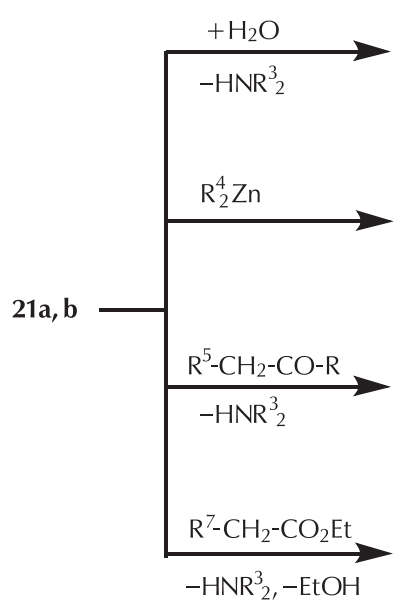<smiles>[R]C(=O)c1ccncc1O</smiles><smiles>[R]=[W]</smiles>

$\mathrm{R}^{4}=\mathrm{CH}_{3}, \mathrm{C}_{2} \mathrm{H}_{5}, \mathrm{C}_{6} \mathrm{H}_{5}$

23

$\mathrm{R}^{4}$<smiles>[R]C1CC2=C(C=C[R]C=C2)OC1([Y])O</smiles>

$\mathrm{R}^{2}=\mathrm{H}$

$\mathrm{R}^{5}=\mathrm{COCH}_{3}, \mathrm{COC}_{6} \mathrm{H}_{5}$

24

$\mathrm{R}^{6}=\mathrm{CH}_{3}, \mathrm{CF}_{3}, \mathrm{C}_{6} \mathrm{H}_{5}$

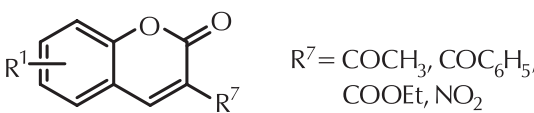

25

Shema 5 - Primjer primjene benzokseta u organskoj sintezi

Scheme 5 - Example of application of benzoxetes in organic synthesis

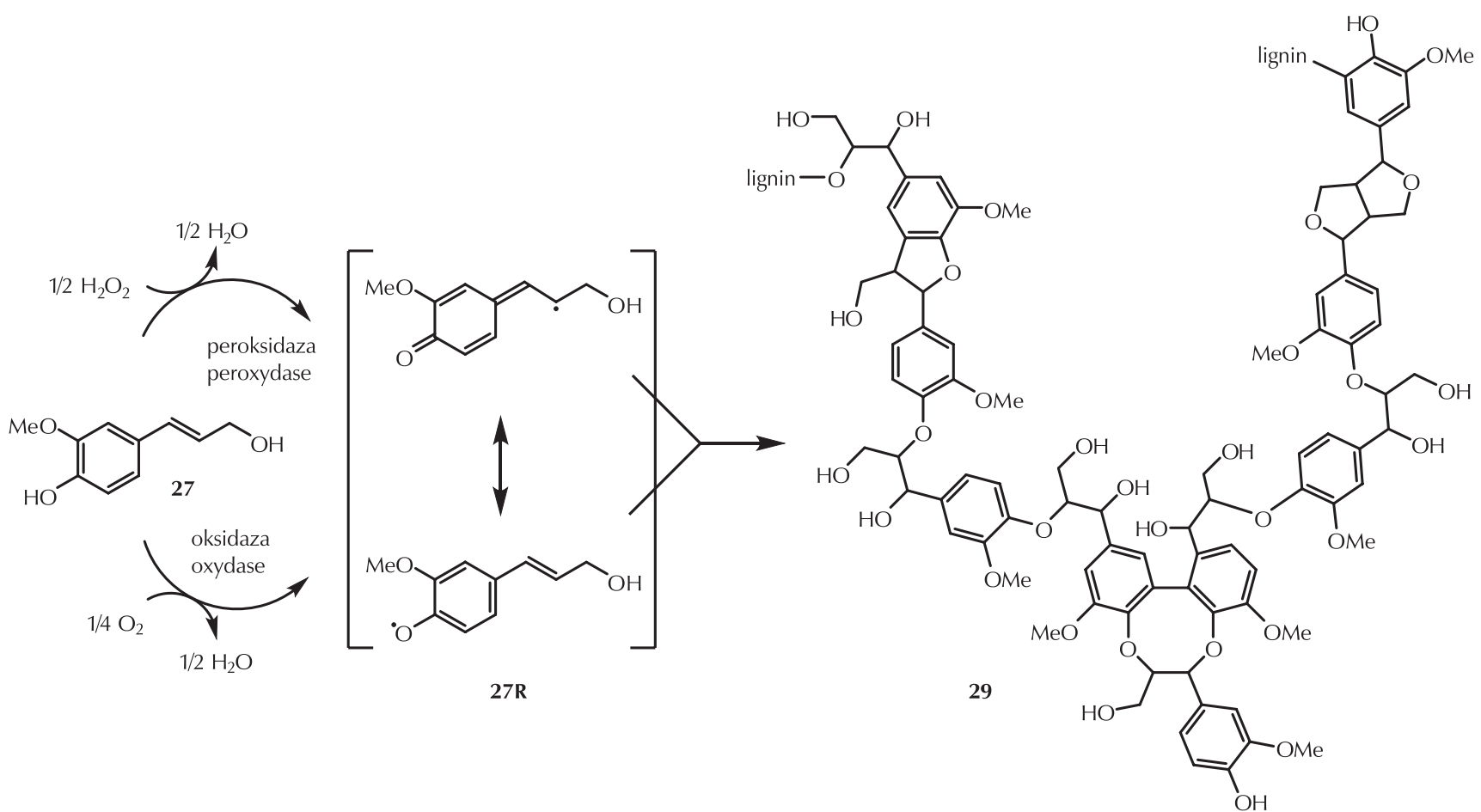

Shema 6 - Biosinteza lignina iz koniferil-alkohola (27) i dio strukture polimera lignina (29)

Scheme 6 - Biosynthesis of lignin from coniferyl-alcohol (27) and part of the lignin polymer structure (29) 
<smiles>OC/C=C/c1ccc(O)cc1</smiles><smiles>COc1cc(/C=C/CO)ccc1O</smiles><smiles>COc1cc(/C=C/CO)cc(OC)c1O</smiles>

Slika 5 - Strukture tri česta monolignola: p-kumaril-alkohol (26), koniferil-alkohol (27) i sinapil-alkohol (28)

Fig. 5 - Structures of three common monolignols: p-cumaryl-alcohol (26), coniferyl-alcohol (27) and sinapyl-alcohol (28)

Celastrol (30a) i njegov metilni ester pristimerin (30b) (slika 6) su QM terpenoidne strukture, a izolirani su iz biljnog materijala. Pokazalo se da imaju antioksidativnu, ${ }^{30}$ protuupalnu, ${ }^{31}$ antiviralnu, ${ }^{32}$ insekticidnu, ${ }^{33}$ antitumorsku ${ }^{30} \mathrm{i}$ anti-Alzheimersku ${ }^{30}$ aktivnost.

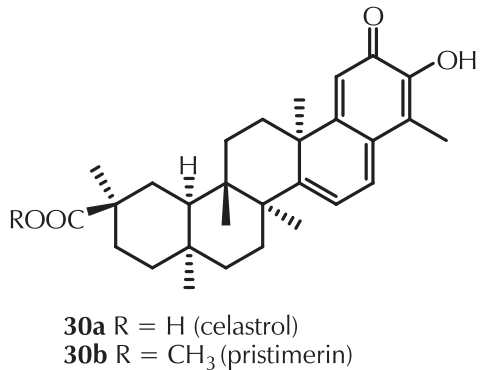

Slika 6 - Strukture celastrola (30a) i pristimerina (30b)

Fig. 6 -Structure of celastrol (30a) and pristimerin (30b)

Još jedan primjer terpenoidne strukture QM-a, koji se može naći u prirodnom materijalu, primjerice ružmarinu, je taksodon (31) te njegov produkt oksidacije 33 (shema 7).
On pokazuje antitumorsku, ${ }^{34}$ antibakterijsku, ${ }^{35}$ antioksidativnu,${ }^{36}$ antifugalnu, ${ }^{37} \mathrm{i}$ insekticidnu aktivnost. ${ }^{38}$

Kendomicin (34) (slika 7) je prirodni QM makrolidne strukture, koji posjeduje antitumorska, antibakterijska i antiosteoporozna svojstva. Prvi je put izoliran iz bakterije Streptomyces violaceoruber. ${ }^{39}$<smiles>CC(=C[C@@H](C)CCC1O[C@H](C2=C(O)C(=O)C(C)=C3C=C(C)C[C@H](C)C[C@H](C)C(O)(C=C2)O3)[C@H](C)[C@@H](O)[C@@H]1C)CC(C)C</smiles>

Slika 7 - Struktura makrolida kendomicina (34)

Fig. 7 - Structure of macrolide kendomycin (34)

\section{Primjena kinon-metida u organskoj sintezi}

Do sad je prikazano kako QM izolirani iz prirodnog materijala pokazuju biološku aktivnost i upotrebljavaju se u svrhu liječenja mnogih bolesti, međutim, QM se često upotrebljavaju i u organskoj sintezi kao vrijedni međuprodukti. Kako se radi o kratkoživućim vrstama koje su vrlo reaktivne, oni zahtijevaju posebno osmišljene prekursore koji će dati QM tek pri određenim reakcijskim uvjetima. Metode generiranja QM-a dijele se na termičke i fotokemijske. Kod fotokemijskih metoda prekursori se pobuđuju zračenjem (svjetlom) te iz pobuđenog stanja kreće reakcija koja rezultira QM-om. Za generiranje QM-a termičkim reakcijama obično se dodaje neki reagens ili QM mogu nastati zagrijavanjem prekursora. U reakciji je najčešće prisutan i dodatni reagens, s kojim generirani QM odmah reagira dajući zanimljive produkte. Osobito su zanimljive i stereoselektivne reakcije u kojima se upotrebljava QM. U dijelu koji slijedi bit će detaljno prikazane važnije termičke reakcije generiranja QM-a i njihova primjena.

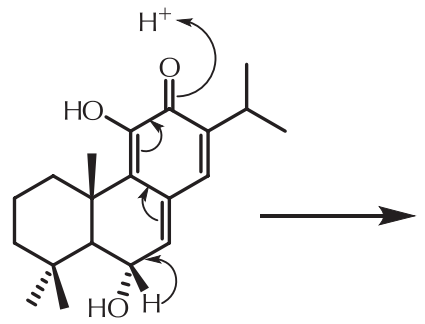

31 (taksodon) 31 (taxodone)<smiles>CC(C)c1cc2c(c(O)c1O)[C@@]1(C)CCCC(C)(C)C1C(=O)C2</smiles>

32<smiles>CC(C)C1=CC2=CC(=O)[C@H]3C(C)(C)CCC[C@]3(C)C2=C(O)C1=O</smiles>

33 (taksodion) 33 (taxodione)

Shema 7 - Struktura taksodona i njegovih produkata oksidacije

Scheme 7 - Structure of taxodone and its oxidation products 


\subsection{Termičke metode generiranja* kinon-metida u organskoj sintezi}

Kako su QM vrlo reaktivne vrste i brzo reagiraju s prisutnim nukleofilima i elektrofilima (osim relativno malog broja stabilnih QM-a), ne mogu se čuvati kao stabilna supstancija, pa je njihova primjena ograničena metodama generiranja in situ. Metode sintetske (termičke) priprave QM-a iz različitih prekursora prikazane su shemom 8. One uključuju oksidaciju fenola ${ }^{40}$ pirolizu dimera kinon-metida, ${ }^{41}$ eliminaciju nitrila iz 1,2-benzoksazina, ${ }^{42}$ eliminacije vode, ${ }^{40}$ alkohola, tiola, karbonilnih spojeva, amina i desililaciju induciranu

" U ovom pregledu upotrebljavat će se izraz "generiranje QM", koji je uobičajen u publikacijama na engleskom jeziku (generation of quinone methides). Izrazi dobivanje/priprava/sinteza QM-a žele se izbjeći s obzirom na to da mogu pogrešno navoditi na zaključak da se radi o spojevima koji su stabilni i izolabilni, što je rijetkost. fluoridom. ${ }^{12 b, 22,43}$ Pregled navedenih metoda detaljnije je prikazan u preglednom članku koji je 2002. godine objavio Pettus, ${ }^{15}$ te se ovdje neće ponavljati. QM imaju primjenu u sintezi raznih benzopirana, ${ }^{44}$ alkil-fenola ${ }^{45}$ u reakcijama adicije $s$ raznim nukleofilima, ${ }^{6,46}$ kod priprave policikličkih heteroaromata, ${ }^{47} \mathrm{u}$ sintezi $\delta-{ }^{48}$ i $\gamma^{-49}$ laktona, nafto- i benzofurana, ${ }^{50}$ kao i u cikloadicijama $[4+2]^{15}$ i $[4+4] . .^{51}$

\subsubsection{Sinteza derivata kromana}

Vjerojatno najraširenija primjena QM-a u sintezi je priprava derivata kromana, koji su različito derivatizirani na benzilnom položaju, a mogu se lako i u dobrim iskorištenjima sintetizirati preko međuprodukata QM-a. Shemom 9 prikazani su uobičajeni sintetski putevi i reakcijski uvjeti koji vode do derivata kromana $\mathbf{4 6} .^{15}$

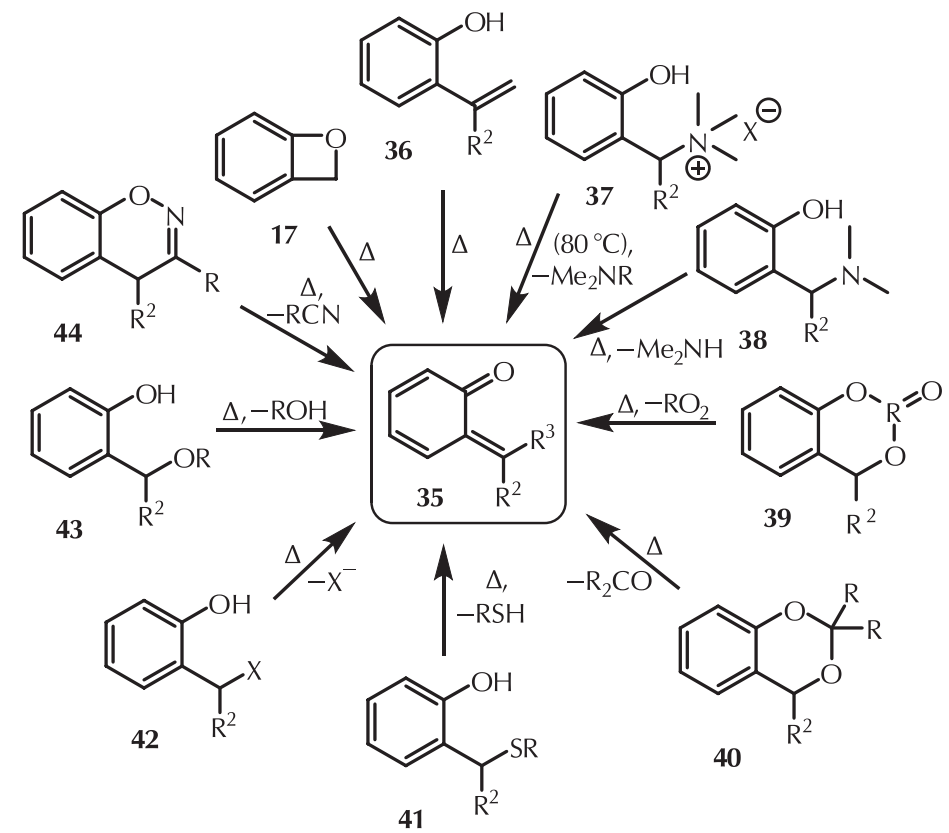

Shema 8 - Metode termičkog generiranja QM-a iz različitih prekursora ${ }^{15}$

Scheme 8 - Thermal methods of QMs generation from different precursors ${ }^{15}$<smiles>[Y]C1OB(P)Oc2ccccc21</smiles>
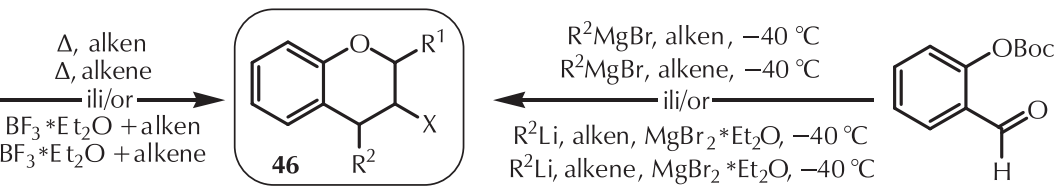

45

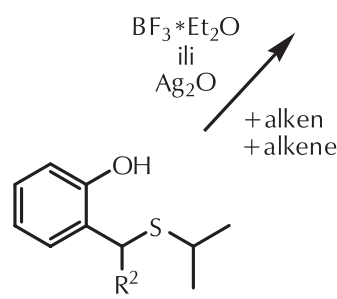

48
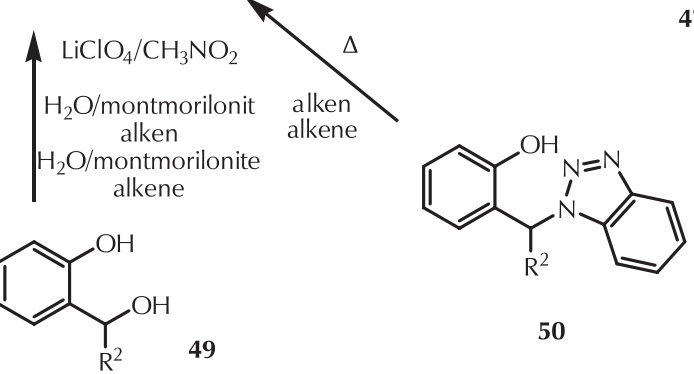

50

Shema 9 - Različiti sintetski pristupi derivatima kromana ${ }^{15}$

Scheme 9 - Different synthetic approaches to chroman derivatives ${ }^{15}$ 
U novije vrijeme razrađene su sintetske metode dobivanja kiralnih kromana preko QM-a koji su stabilizirani kompleksiranjem s metalima (Cu, Pd, Ir, Os). Reakcije se provode uz visoke enantioselektivnosti i dijastereomerne viškove. ${ }^{20}$ Takve reakcije zahtijevaju dodatni kiralni ligand koji u katalizi služi kao kiralna informacija. Osim tog tipa reakcija, razvijene su i asimetrične reakcije koje su kontrolirane strukturom samog reaktanta koji ulazi u reakciju. Tako su Pettus $i$ sur. upotrebom kiralnih enolnih etera sintetizirali različite derivate kromana u visokim iskorištenjima i s visokim dijastereomernim viškovima (shema 10). ${ }^{52}$

\subsubsection{Oksidacijom inducirano generiranje kinon-metida iz estera arilbornih kiselina}

Peng $i$ sur. pripravili su seriju estera arilbornih kiselina s raznim supstituentima na benzenskom prstenu kako bi studirali njihov utjecaj na stabilnost nastalih QM-a. ${ }^{53} \mathrm{Na}$ benzilnim položajima su amonijeve skupine koje služe kao dobre odlazeće skupine. Primjer takvog derivata je disol 54 koja nakon oksidativnog cijepanja veze ugljik-bor s
$\mathrm{H}_{2} \mathrm{O}_{2}$ daje odgovarajući fenol 55 iz kojeg spontano nastaje QM 56 (shema 11). Autori navode da su uvjeti generiranja QM-a tom metodom vrlo blagi i fiziološki, pa bi se ta metoda mogla upotrijebiti za križno povezivanje DNA, dajući adukt 57. lako takva reakcija otvara mogućnost za primjenu, primjerice u terapiji tumora jer u konačnici dovodi do apoptoze, ${ }^{2}$ autori nažalost nisu proveli i studije biološke aktivnosti.

\subsubsection{Sinteza benzo- i naftofurana reakcijama $N$ - i S-ilida s kinon-metidima}

Sintetski pripravljeni derivati koji u svojoj strukturi sadrže skelet 2,3-dihidrobenzofurana do sad su pokazali jako dobru biološku aktivnost, a njihov skelet također je i dio struktura nekih prirodnih produkata. ${ }^{54}$ Zhou i sur. nedavno su razvili vrlo učinkovitu metodu sinteze derivata 2,3-dihidrobenzofurana preko o-QM-a. ${ }^{55}$ Polazni spojevi za tu sintezu su derivati 2-tosilalkilfenola, čiju su jednostavnu sintezu isti autori osmislili i razradili. Nakon optimizacije reakcije, u reakciji sa sumpornim ilidima pripravili su ra-

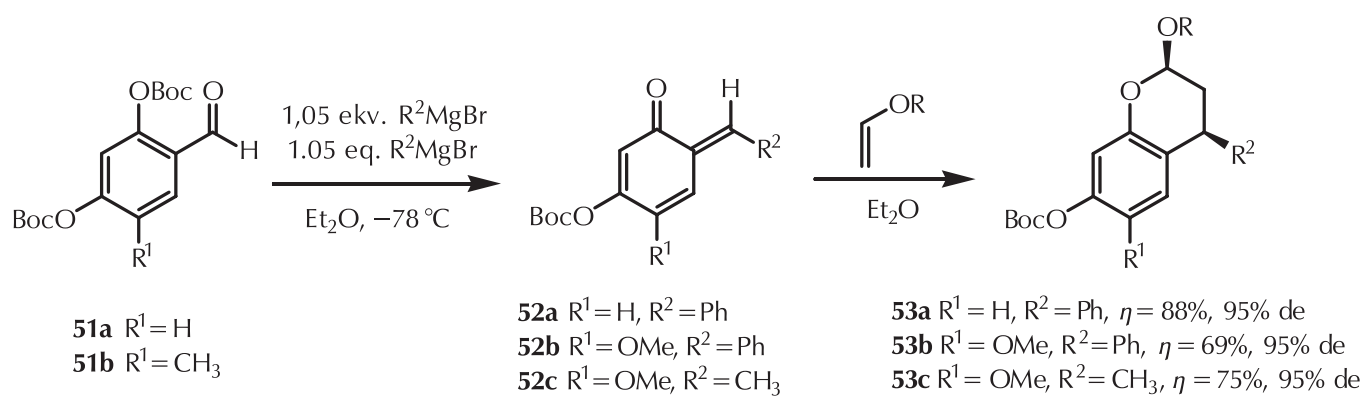

Shema 10 - Dijastereoselektivna reakcija kiralnih enolnih etera s o-QM-om ${ }^{52}$

Scheme 10 - Diastereoselective reaction between chiral enol-ethers and o-QM ${ }^{52}$

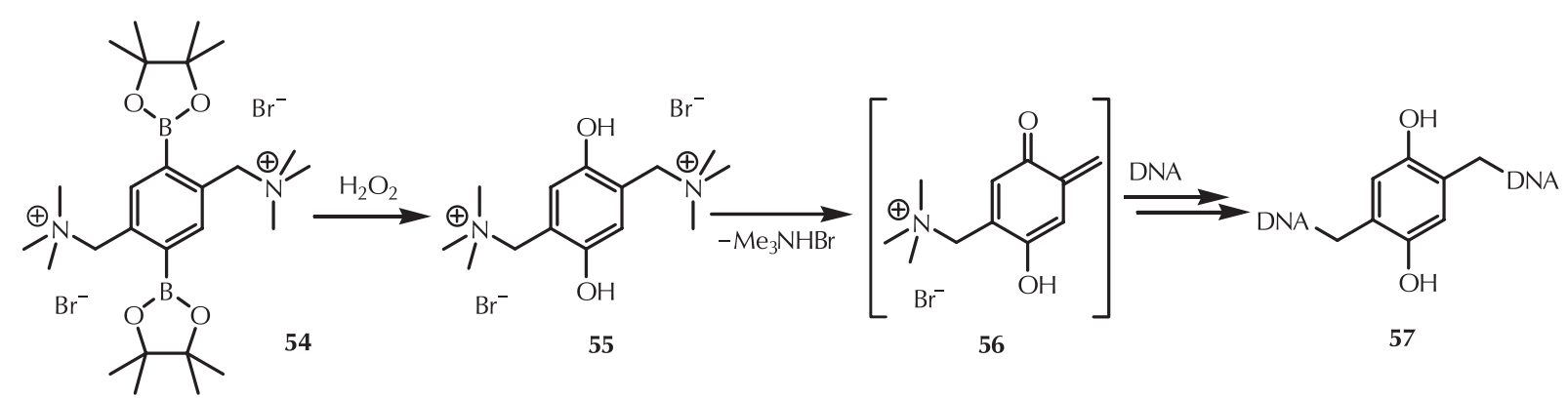

Shema 11 - Generiranje QM-a iz estera arilbornih kiselina i njihova primjena u križnom povezivanju DNA ${ }^{53}$ Scheme 11 - Generation of QM from ester of arylboronic acid and its application in DNA cross-linking ${ }^{53}$ 
zličito supstituirane 2,3-dihidrobenzofurane $\mathbf{6 2}$ u izvrsnim iskorištenjima (shema 12).

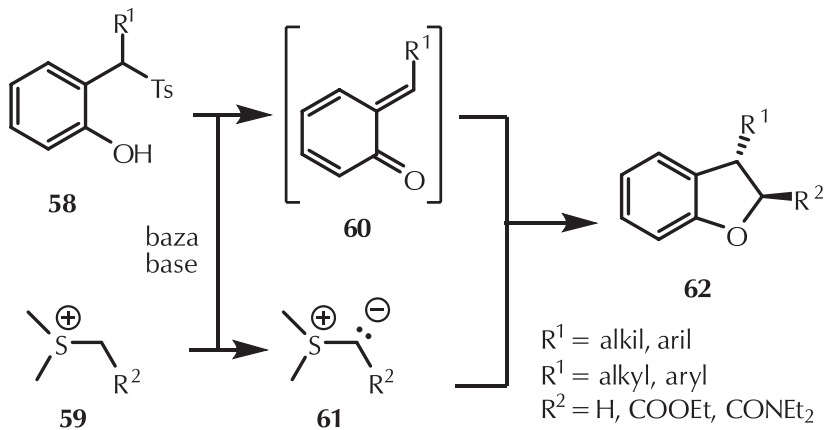

Shema 12 - Opća strategija sinteze 2,3-dihidrobenzofurana preko međuprodukata QM-a ${ }^{55}$

Scheme 12 - A general strategy for the synthesis of 2,3-dihydrobenzofurane via QM intermediate ${ }^{55}$

Dodatno, 1,2-dihidronafto[2,1-b]furani ističu se svojom upotrebom u medicinskoj kemiji zbog svoje raznolike farmakološke aktivnosti. ${ }^{56}$ Iz tog razloga, Osyanin sa suradnicima radio je na osmišljavanju efikasnijeg i bržeg puta njihove sinteze. ${ }^{50} \mathrm{U}$ tom slučaju upotrijebljeni su dušikovi ilidi 64 koji s QM-om nastalim eliminacijom iz Mannichovih baza 63 daju produkte 65 u dobrim iskorištenjima (shema 13).

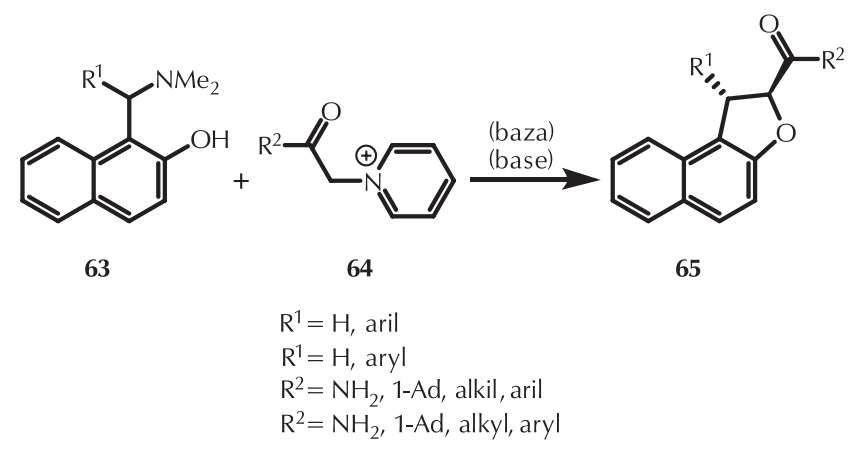

Shema 13 - Sinteza 1,2-dihidronafto[2,1-b]furana preko međuprodukata QM-a u reakciji s dušikovim ilidima. Baza u nekim slučajevima nije potrebna, a kad je, onda se primjenjuje DBU ili TMG. ${ }^{50}$

Scheme 13 - Synthesis of 1,2-dihydronaphthto[2,1-b]furane via QM intermediate in the reaction with nitrogen ylides. In some cases, the base is not necessary, but when it is, DBU or TMG is used. ${ }^{50}$

\subsubsection{Sinteza furo[3,2-c]benzopirana}

Furanom srašteni heterocikl furo[3,2-c]benzopiran predstavlja ključan strukturni motiv u mnogim prirodnim spojevima i biološki aktivnim spojevima. ${ }^{57}$ Zhao i sur. pokazali su da se takvi spojevi složene strukture mogu pripraviti hetero-Diels-Alderovom reakcijom iz različito supstituiranih salicilaldehida 66 i $\alpha$-preniliranih alkohola 67 uz prisutnost katalitičke količine bezvodne kiseline (shema 14). ${ }^{58}$ Reak- cija je optimizirana i potom ispitana na većem broju supstrata. Iskorištenja variraju od dobrih do izvrsnih, a dijastereoselektivnost je vrlo visoka, nastaju većinom produkti $\mathbf{7 0}$ koji su trans-srašteni.

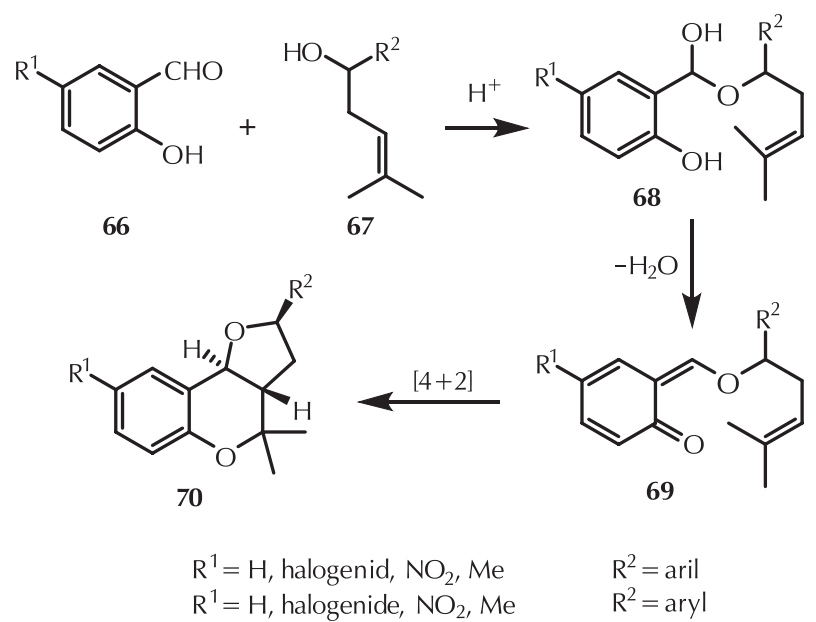

Shema 14 - Sinteza trans-furo[3,2-c]benzopirana preko međuprodukta QM-a 69

Scheme 14 - Synthesis of trans-furo[3,2-c]benzopyran from QM intermediate $\mathbf{6 9}$

\subsubsection{Sinteza ciklopropilindola}

Derivati ciklopropilindola su skupina spojeva koja pokazuje iznimnu biološku aktivnost kod liječenja raka, ${ }^{59}$ a također je pokazano da inhibiraju i reverznu transkriptazu kod virusa HIV. ${ }^{60}$ Svoju biološku aktivnost ti spojevi najvjerojatnije temelje na QM-ima kao međuproduktima u mehanizmu njihova djelovanja. Skibo i sur. ${ }^{61}$ studirali su generiranje ciklopropilindola iz spoja 71 (shema 15), koji ima strukturu sličnu mitozenu. Kod mitozena je poznato da dolazi do eliminacije odlazeće skupine, što rezultira stvaranjem QM-a koji može alkilirati molekulu DNA. ${ }^{62}$ Spoj 71 poslužio je u studijama ${ }^{13} \mathrm{C}$ NMR za praćenje nastanka QM-a 73 i njegove reakcije s nukleofilima.
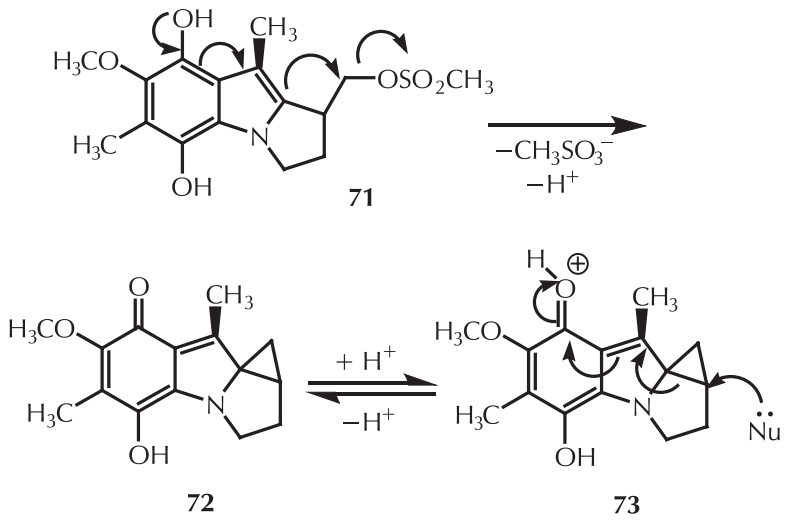

Shema 15 - Generiranje QM-a ciklopropilindola Scheme 15 - Generation of cyclopropylindole QM 
Također je pokazano da QM 73 selektivno alkilira DNA molekulu na položaju N(7) gvanina, što je vrlo važno jer pokazuje primjenjivost u biološkim sustavima, npr. kod liječenja karcinoma.

\subsubsection{Sinteza spirociklopropana}

Literaturni primjeri upotrebe $p$-QM-a u sintezi mnogo su rjeđi od primjera upotrebe o-QM-a. Takve sinteze uključuju 1,6-konjugiranu adiciju, ${ }^{63}$ reakcije [4+2]-anelacije ${ }^{64}$ i [3+2]-anelacije. ${ }^{65}$ Osobito zanimljiv primjer upotrebe p-QM-a je u sintezi spirociklopropana koju je opisao Fan sa svojim suradnicima (shema 16). ${ }^{66}$

Reakcija se koristi stabilnim p-QM-om 74 koji u reakciji sa sumporovim ilidom $\mathbf{7 5}$ daju odgovarajuće spirociklopropane 77. Uobičajeno bi reakcija $p$-QM-a sa sumporovim ilidom (1,6-konjugirana adicija) trebala rezultirati derivatima fenola kao produktima, no ovdje je struktura sumporova ilida 75 posebno osmišljena tako da reakcija daje ciklopropanske produkte. Rješenje se temelji na tome da sumporov ilid na nukleofilnom ugljikovu atomu ima vezanu dobru odlazeću skupinu, koja iz međuprodukta $\mathbf{7 6}$ izlazi kako se ciklopropanski prsten zatvara (shema 16).

\subsubsection{Sinteza spiro[4.5]deka-6,9-dien-8-ona}

Spiro[4.5]deka-6,9-dien-8-on je strukturni motiv koji je dio velikog broja prirodnih spojeva i molekula koje su pokazale biološku aktivnost pa je također i vrlo važan međuprodukt u sintezi prirodnih spojeva. ${ }^{67}$ Sintezu takvog skeleta preko međuprodukta $p$-QM-a proveli su Lin i Yao sa suradnicima ${ }^{68}$ u reakciji [3+2] anelacije između $p$-QM-a i vinilciklopropana. Reakcija je katalizirana katalizatorom koji sadrži kiralni fosfin-tioureidni ligand koordiniran na $\operatorname{Pd}(0)$ (shema 17). Iskorištenja tih reakcija su visoka, kao i dijastereoselektivnost, a reakcije je moguće provoditi i na većoj skali.

\subsubsection{Sinteza složenih policličkih molekula}

U svrhu priprave analoga tetraciklinskih antibiotika, Kucklaender je sa svojim suradnicima sintetizirao Mannichove baze 82. Međutim, pokazalo se da kod njih dolazi do termički inducirane dimerizacije čiji su produkti složeni spiropoliciklički spojevi 84 (shema 18). ${ }^{69}$ Međuprodukt te reakcije je QM 83, što je potaknulo ideju da bi ti spojevi mogli posjedovati antitumorsku aktivnost s obzirom na to da slični citostatici, kao što je mitomicin C ili antraciklini, svoje djelovanje temelje upravo na mogućnosti generiranja QM-a.,

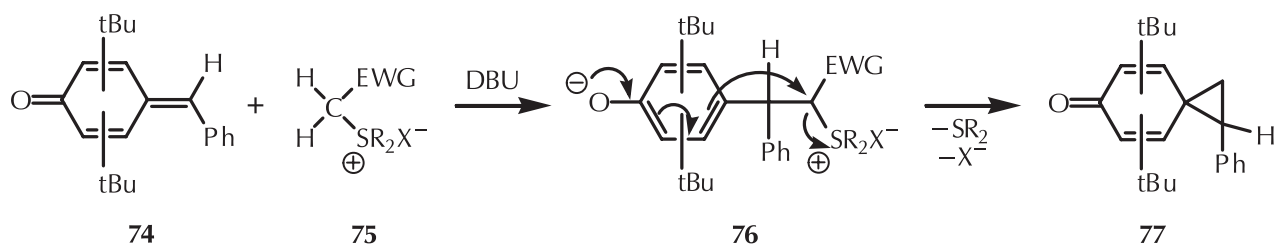

Shema 16 - Sinteza spirociklopropana preko p-QM-a

Scheme 16 - Synthesis of spirocyclopropane via p-QM<smiles>[R]C=C1C=C([R])C(=O)C([R])=C1</smiles>

78

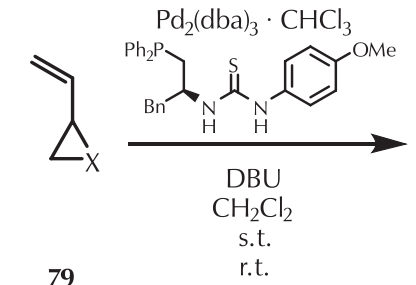

79

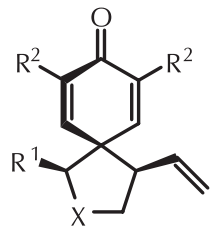

$\mathrm{R}^{1}=$ aril

$\mathrm{R}^{1}=$ aryl

$\mathrm{R}^{2}=\mathrm{Me}, i \mathrm{Pr}, t \mathrm{Bu}$

$\mathrm{X}=\mathrm{C}\left(\mathrm{CO}_{2}\right.$ alkil)

$\mathrm{X}=\mathrm{C}\left(\mathrm{CO}_{2}\right.$ alkyl)

Shema 17 - Sinteza derivata spiro[4.5]deka-6,9-dien-8-ona preko međuprodukta p-QM-a ${ }^{68}$

Scheme 17 - Synthesis of spiro[4.5]deca-6,9-diene-8-one derivatives via p-QM intermediate ${ }^{68}$ 
<smiles>[R]c1c(C(=O)OC)c2cc(O)c3cc4ccccc4cc3c2n1[R]</smiles>

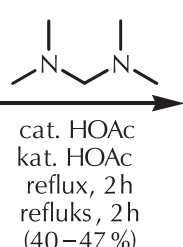
81

$\mathrm{R}^{1}=\mathrm{alkil}$, aril $\mathrm{R}^{1}=$ alkyl, aryl $\mathrm{R}^{2}=$ Me ili $\mathrm{Ph}$ $\mathrm{R}^{2}=\mathrm{Me}$ or $\mathrm{Ph}$<smiles>[R]c1c(C(=O)OCC)c2c(CNC)c(O)c3cc4ccccc4cc3c2n1[R]</smiles>

82<smiles></smiles>

84

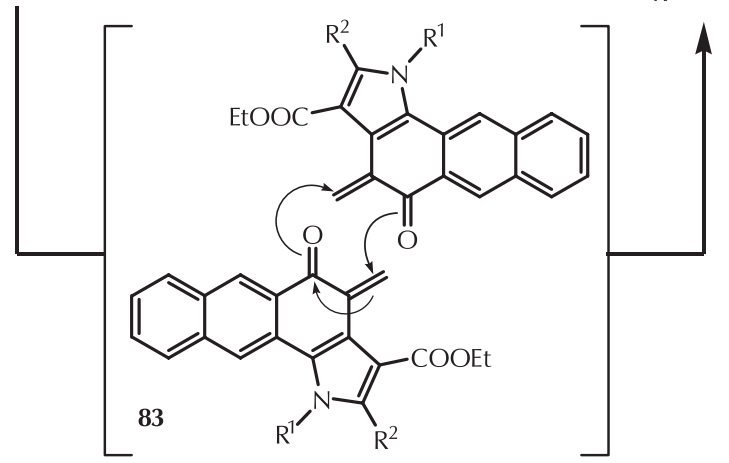

Shema 18 - Sinteza fenolnih Mannichovih baza 82 i Diels-Alderova dimerizacija međuprodukata QM-a 83 Scheme 18 - Synthesis of the phenolic Mannich bases 82 and Diels-Alder dimerization of intermediate o-QM 83

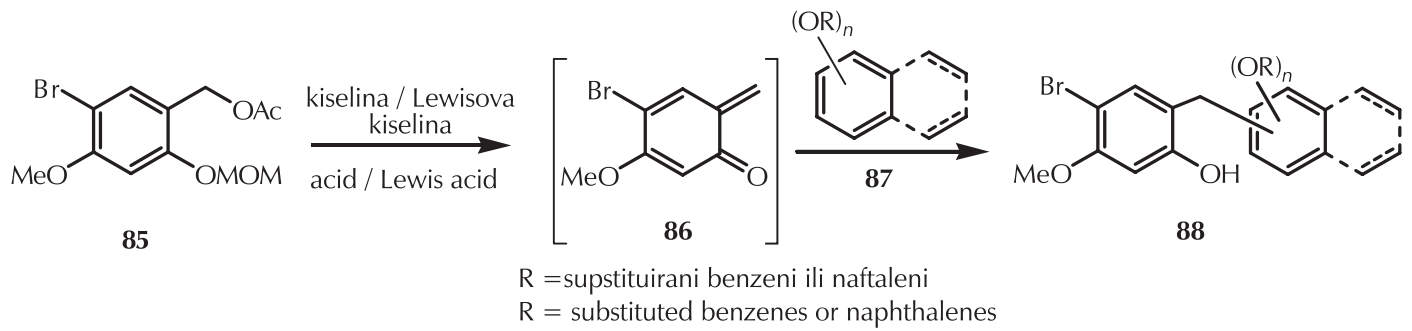

Shema 19 - Sinteza derivata diarilmetana preko međuprodukata QM-a Scheme 19 - Synthesis of diarylmethane derivatives via QM intermediates

\subsubsection{Sinteza diarilmetana}

Phakhodee i Ploypradith su sa svojim suradnicima razvili metodu vrlo jednostavne sinteze diarilmetana preko međuprodukata $\mathrm{QM}-\mathrm{a} .{ }^{70} \mathrm{U}$ reakciji $\mathrm{QM}-\mathrm{a} \mathbf{8 6}$ geniriranim iz prekursora $85 \mathrm{~s}$ elektronima bogatim aromatskim spojevima 87 nastaju diarilmetani 88 (shema 19).

Ova reakcija je optimizirana te je pokazano da je najpogodnija Lewisova kiselina $p-\mathrm{TsOH}_{\mathrm{H}}$ apsorbirana na silikagel. $\mathrm{Na}$ velikom broju supstrata pokazana je primjenjivost reakcije pri čemu su iskorištenja na produktima bila izvrsna.

\subsubsection{Sinteza funkcionalnih polimera}

Iznimno zanimljiva primjena QM-a je kod funkcionalnih polimera. Phillips i sur. pripravili su polimere koji su zapravo prekursori QM-a. ${ }^{71}$ Takav polimer može se ugraditi u plastiku i služiti detekciji određenih kemijskih signala koji se odvijaju na površini plastika-otopina. Odziv predstavlja signalom inducirana depolimerizacija koja je kontinuirana i počinje na mjestu detekcije, a završava na samom kraju polimernog lanca (slike 8 i 9). Na taj način takvi polimeri omogućavaju amplifikaciju signala.

Autori studije su kao detekcijsku jedinicu upotrebljavali sililni (TBS) ili alilni eter. Pokazali su da mali komadić plastike koji sadrži takav polimer postaje detektor za fluoridne ione, odnosno $\mathrm{Pd}(0)$ prisutan u otopini. Time je dokazan princip, a mogućnosti daljnje modifikacije takvog materijala i njegove primjene su nesagledive.

\subsubsection{Asimetrična alkilacija aldehida}

Jørgensen $i$ sur. studirali su i optimizirali reakciju $\alpha$-alkilacije aldehida 89 preko 1,6-konjugirane adicije enamina na p-QM-u 90, koja rezultira nastankom $\alpha$-diarilmetan-supstituiranih aldehida 91, koji imaju dva susjedna kiralna 

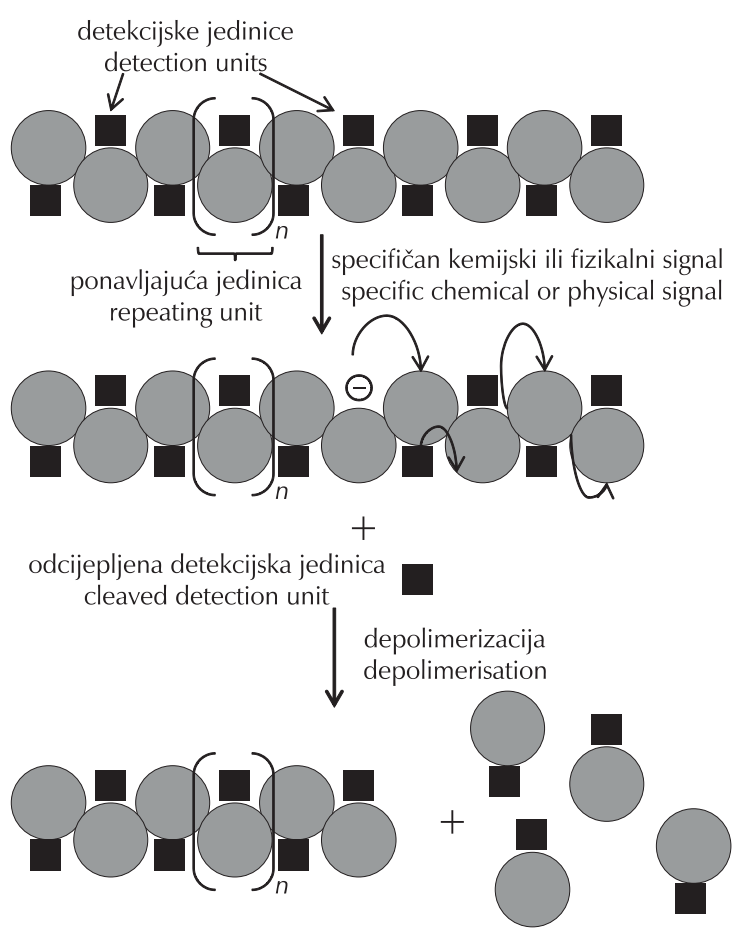

Slika 8 - Funkcionalni polimer (čvrsta plastika) koji pokazuje svojstvo amplifikacije specifičnih signala na površini polimer-tekućina

Fig. 8 - Functional polymer (rigid plastics) showing amplified responses to specific signals at the solid-liquid interface

ugljikova atoma (shema 20). ${ }^{63 e}$ Dijastereo-kontrola reakcije je dobra (dr $1.1: 1$ do $9.6: 1$ ), a enantioselektivnost odlična (88-99 \%, u najvećem broju slučajeva $99 \%$ ). Kao kiralna informacija u reakciji služi kiralni katalizator 92-94 koji su isti autori razvili i optimizirali mu strukturu.<smiles>[Y]C=C1C=C([Y])C(=O)C([Y])=C1</smiles>

$\mathrm{R}^{1}=$ alkil, alkilaril

$\mathrm{R}^{1}=$ alkyl, alkylaryl

$\mathrm{R}^{2}=\mathrm{Me}, t-\mathrm{Bu}$

$\mathrm{R}^{3}=$ alkili, arili

$\mathrm{R}^{3}=$ alkyl, aryl

$\mathrm{R}^{4}=\mathrm{TMS}, \mathrm{Si}(\mathrm{Ph})_{3}$
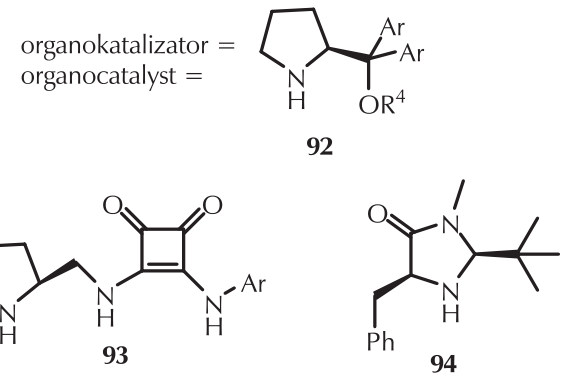

Shema 20 - Enantioselektivna reakcija p-QM-a s aldehidima u prisutnosti kiralnog katalizatora

Scheme 20 - Enantioselective reaction of $p$-QM with aldehydes in the presence of a chiral catalyst

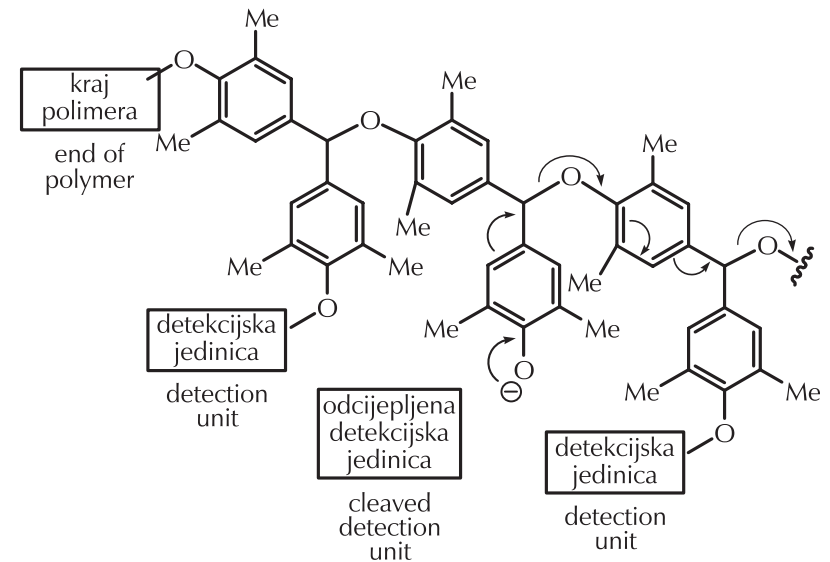

Slika 9 - Specifična struktura polimernog lanca omogućuje amplifikaciju signala zbog lančane reakcije depolimerizacije uzrokovane signalom iz otopine

Fig. 9 - Specific structure of the polymer backbone which allows signal amplification due to the chain depolimerisation reaction caused by external stimuli from the solution

Primjenom te metode produkti 91 su postali lako dostupni te se mogu razmatrati kao gradivni blokovi za složenije molekule u kojima je potrebna točno određena stereokemija.

\subsubsection{Fluoridom inducirana desililacija}

Vrlo važna metoda generiranja QM-a je reakcija fluoridom inducirane desililacije koju su razvili Rokita i sur. Fenolna $\mathrm{OH}$ skupina spoja 95 zaštićena je sililnom zaštitnom skupinom, a na oba o-benzilna položaja su vezane acetilne skupine. U reakciji s fluoridnim ionima dolazi do desililacije (uklanjanja zaštitne skupine TBDMS) koja je praćena eliminacijom acetilne skupine, pri čemu nastaje QM 96. Pokazano je da tako generirani QM može alkilirati i križno povezati molekulu DNA, pri čemu nastaju adukti tipa $\mathbf{9 7}$ (shema 21). ${ }^{12,22,43}$

Rokita i sur. su, u istraživanjima koja su uslijedila, ispitivali i križno povezivanje DNA s derivatom 98 (slika 10). Spoj 98 je zapravo konjugat strukture iz koje se može generirati QM i akridina, za koji je poznato da je dobar interkalator između parova baza DNA. Svojstvo interkalacije ovdje je iskorišteno u svrhu dovođenja reagensa na mjesto gdje se treba dogoditi kemijska reakcija kad se generira QM. Drugim riječima, akridin služi kao svojevrsno "sidro". Tim pristupom postignuto je 64 puta više križnog povezivanja DNA nego u slučaju kad je upotrijebljen spoj bez akridinske jedinice. ${ }^{43 \mathrm{~h}}$ Autori su također pokazali da reakcija QM-a s nukleobazama može biti reverzibilna, te zbog toga u konačnici u reakciji s nukleobazama nastaju produkti koji su termodinamički najstabilniji. ${ }^{43 c}$ Pokazano je također da se na stabilnost stvorenih adukata uvelike može utjecati promjenom supstituenata na QM-u. ${ }^{12 b-c}$ 


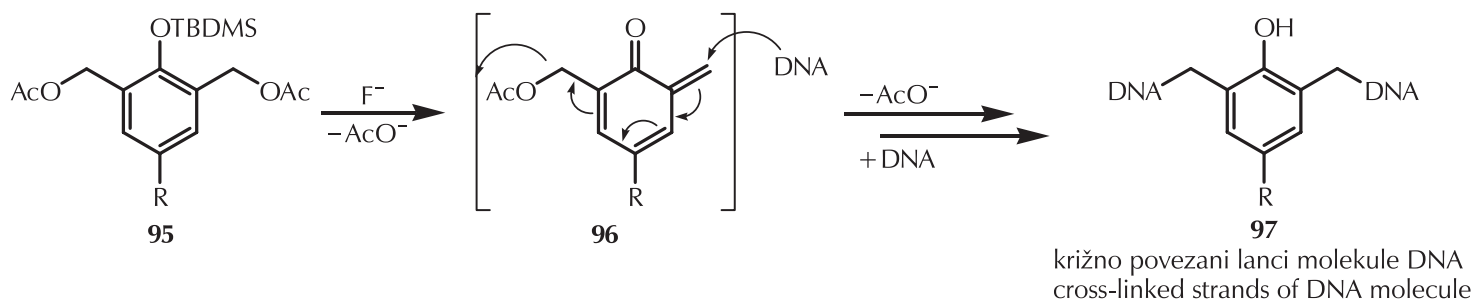

Shema 21 - Generiranje QM-a 96 iz prekursora 95 reakcijom desililacije inducirane fluoridom i reakcija nastalog QM-a s DNA

Scheme 21 - Generation of QM 96 from precursor 95 by fluoride-induced desilylation reaction and reaction of generated QM with DNA<smiles>CCCCOc1c(COC(C)=O)cc(CCC(=O)NCCNc2c3ccccc3nc3ccccc23)cc1COC(C)=O</smiles>

98

Slika 10 - Struktura konjugata prekursora QM-a i interkalatora akridina $^{43 \mathrm{~h}}$

Fig. 10 - Structure of QM precursor-acridine intercalator conjugate j3h $^{4}$

Primjena ovog pristupa u biološkim sustavima uvelike je ograničena toksičnošću fluoridnog aniona (kod prosječnog čovjeka trovanje fluoridima uzrokuju doze veće od 32 - 64 miligrama fluoridnih iona po kilogramu tjelesne mase), ${ }^{72}$ ali se kroz brojna istraživanja opisana u literaturi pokazalo da je ta metoda vrlo korisna za ispitivanja biološke aktivnosti sintetski generiranih QM in vitro. ${ }^{12 b, 22,43}$

\subsection{Primjene kinon-metida u totalnoj sintezi}

Kinon-metidi pokazali su se prilično korisnim kod sinteze velikog broja različitih molekulskih skeleta, te stoga ne čudi da je njihova primjena prepoznata i u području totalne sinteze. Ovdje će biti dan pregled primjena QM-a u totalnoj sintezi.

\subsection{1. (+)-R-tolterodin i (+)-R-mimosifoliol}

Rad Selenskog i Pettusa, ${ }^{52 a}$ u kojem su opisali enantioselektivnu cikloadiciju kiralnog enolnog etera na o-QM, bio je osnova za primjenu QM-a u totalnoj sintezi (+)-tolterodina (99) i (+)-mimofiloliola (100) (slika 11). ${ }^{73}$ Tim metodama dobiven je novi stereocentar $\mathrm{u}$ visokom enantiomernom višku.<smiles>Cc1ccc(O)c([C@@H](CCN(C(C)C)C(C)C)c2ccccc2)c1</smiles>

99<smiles>C=C[C@H](c1ccccc1)c1cc(OC)c(O)cc1OC</smiles>

100
Slika 11 - Struktura $(+)-(R)$-tolterodina i $(+)-(R)$-mimosifoliola

Fig. 11 -Structure of $(+)-(R)$-tolterodine and $(+)-(R)$-mimosifoliol

\subsubsection{Rubionkolin $B$}

Trauner $i$ sur. razvili su sintetski pristup spojevima koji u svojoj strukturi sadrže kromen preko međuprodukata QM-a. ${ }^{74}$ Na temelju tih saznanja uspješno su osmislili i proveli sintezu kompleksnog naftohidrokinonskog dimera rubinokolona B 101 (slika 12) koji je ranije izoliran iz korijenja biljaka Rubia oncotricha i R. cordifolia. Pripravci tih biljaka tradicionalno se primjenjuju u kineskoj i ajurvedskoj medicini te se smatra da je spoj $\mathbf{1 0 1}$ jedna od djelatnih tvari u tim pripravcima. ${ }^{75}$ Sinteza je provedena u 13 koraka s ukupnim iskorištenjem od 3,3\%.

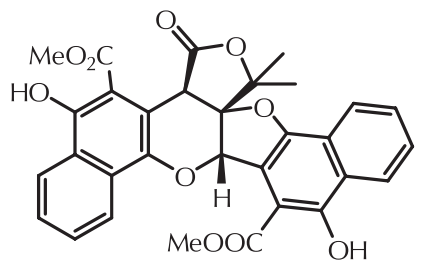

101

Slika 12 - Struktura rubionkolina B Fig. 12 - Structure of rubioncolin B

\subsection{3. ( \pm )-Vatikanol $A$}

Još jedan zanimljiv primjer je totalna sinteza ( \pm )-vatikanola A (102, slika 13), za koji se ranije pokazalo da je iznimno učinkovit u suzbijanju parazita, ali i da ima utjecaj na dija- 
betes s obzirom na to da inhibira povišenje koncentracije šećera u krvi. ${ }^{76} \mathrm{U}$ totalnoj sintezi tog prirodnog spoja reaktivni QM generiran reakcijom oksidacije uz DDQ poslužio je kao međuprodukt ključan za zatvaranje sedmeročlanog prstena, a to je ujedno bio i ključni korak u sintezi tog složenog molekulskog skeleta.

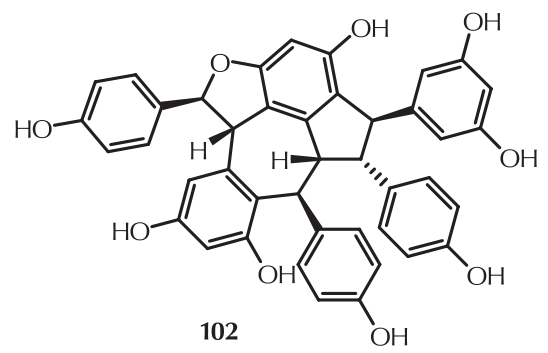

Slika 13 - Struktura vatikanola A

Fig. 13 - Structure of vaticanol A

\subsubsection{Polemanoni B i C}

Lindsley i sur. objavili su prvu totalnu sintezu polemanona B i C (103 i 104, slika 14), prirodnih policikličkih spojeva izoliranih iz korijena biljke Polemannia montana. Ključni korak te sinteze bio je stvaranje veze između dvaju fenola. To je lako postignuto primjenom katalitičkog sustava koji su razvili ti autori. On uključuje generiranje QM-a i reakciju [4+2] cikloadicije, pri čemu se zatvara složeni policikl koji se sastoji od četiri sraštena šesteročlana prstena i peteročlanog prstena. Iskorištenja reakcija su 15 \% (5 koraka, 103) i $31.5 \%$ (4 koraka, 104). ${ }^{77}$<smiles>COC1=C2OCO[C@]23Cc2c(cc4c(c2OC)OCO4)[C@@]2(C)[C@@H](C)[C@@H](C)CC(C1=O)[C@@]32C</smiles>

103<smiles>COC1=C(OC)[C@]2(OC)Cc3c(cc(OC)c(OC)c3OC)[C@@]2(C)[C@@H]2CC(C)[C@H](C)CC12</smiles>

104
Slika 14 - Strukture polemanona B i polemanona C

Fig. 14 - Structures of polemannone B and polemannone C

\subsubsection{Berkelijska kiselina}

Prirodni spoj, berkelijska kiselina (105, slika 15), prvi je, iz prirodnog materijala, izolirao Stierle sa suradnicima 2006. godine. Radi se o sekundarom metabolitu, koji proizvodi vrsta Penicillium, koja uspijeva u jezeru Berkeley Pit u Montani. ${ }^{78}$ Testiranja biološke aktivnosti pokazala su da blokira enzime cisteinsku proteazu, kaspazu-1 i metaloproteinazu-3. Dobra i selektivna citotoksičnost pokazala se na staničnim linijama osobito agresivnog raka jajnika OVCAR-3. ${ }^{78}$ Moguće primjene tog spoja pokazuju veliku važnost razvoja njegove totalne sinteze. Pettus $i$ sur. osmislili su formalnu sintezu spoja, koja uključuje QM kao međuprodukte. ${ }^{79}$

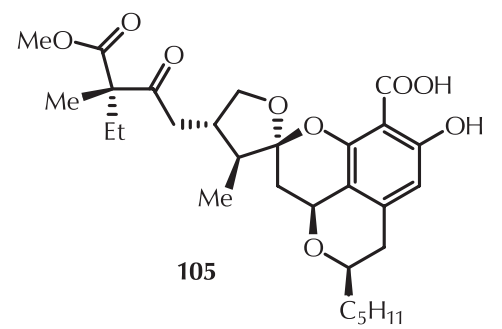

Slika 15 - Struktura (-)-berkelijske kiseline

Fig. 15 - Structure of (-)-berkelic acid

Ključni korak te sinteze je bazom katalizirano otvaranje laktona 106 te adicija QM-a 107 generiranog in situ na kiralni enolni eter $\mathbf{1 0 8}$ (shema 22). Stereokemija spoja 108 određuje stereoselekivnost reakcije, te nastaju spojevi 109 u iskorištenjima $60-65 \%$ s dijastereomernim omjerom do $3: 1$.

\subsubsection{Penifenoni $A-D$}

Penifenoni su prirodni spojevi izolirani iz plijesni Penicillium dipodomyicola HN4-3A te je za njih nađeno da imaju inhibitornu aktivnost prema bakteriji Mycobacterium tuberculosis. Totalnu sintezu penifenona A-D (111-114) proveli su George i sur. iz jednog prekursora, QM 110, u reakcijama hetero-Diels-Alder (111), Michaelove adicije (112 i 114) i elektrofilne aromatske supstitucije praćene<smiles>O=C1Cc2cc(OCc3ccccc3)c(I)c(O)c2CO1</smiles>

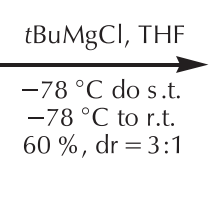

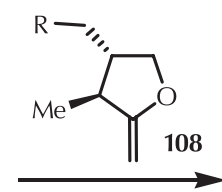

107<smiles>CC[C@H]1CO[C@]2(CCc3c(CC(=O)O)cc(OCc4ccccc4)c(I)c3O2)O1</smiles>

109

Shema 22 - Ključni korak sinteze berkelijske kiseline odvija se preko QM-a 107

Scheme 22 - The key step of berkelic acid synthesis takes place via QM 107 


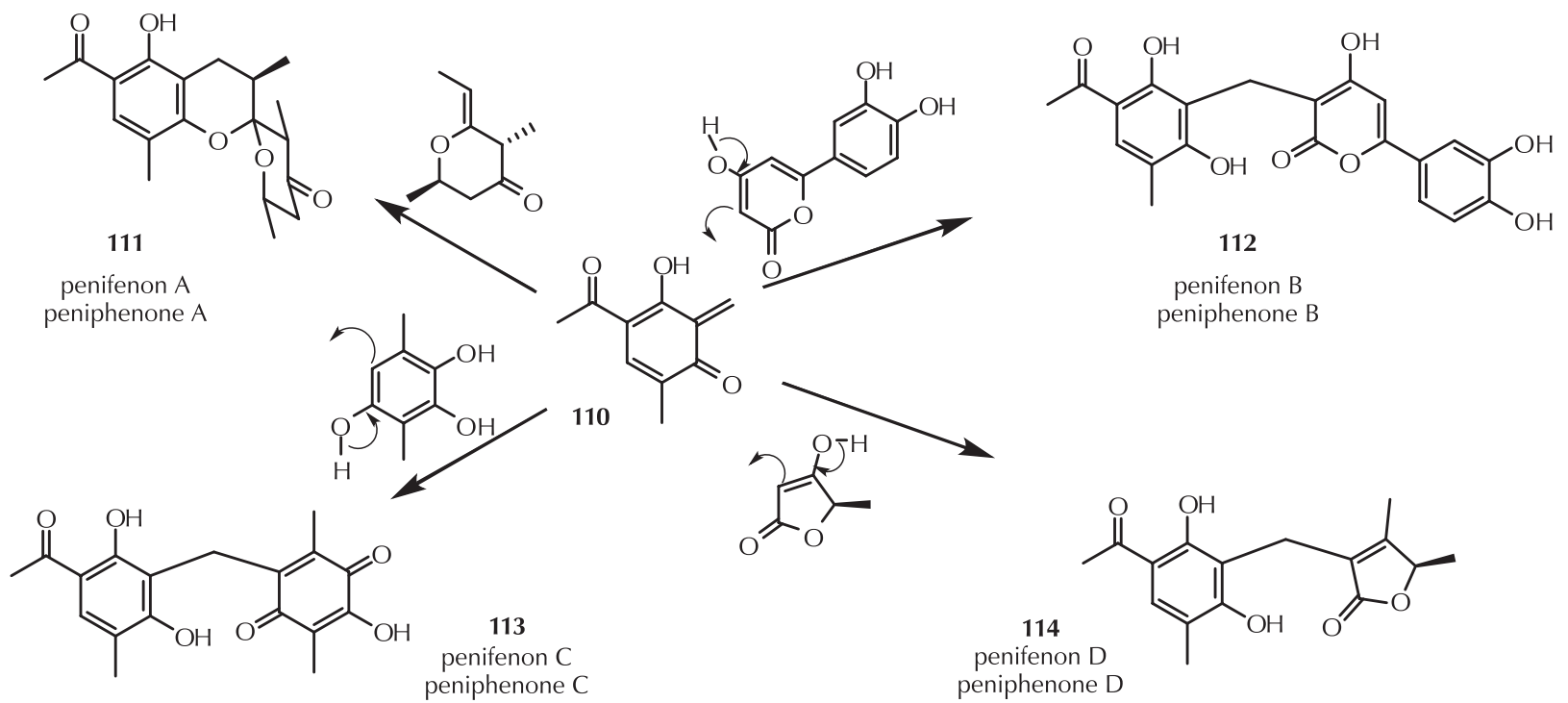

Shema 23 - Sinteza penifenona A-D (111-114) preko zajedničkog međuprodukta QM-a (110)

Scheme 23 - Synthesis of peniphenones A-D (111-114) via common QM intermediate (110)

autooksidacijom (113) (shema 23). ${ }^{80}$ Ta strategija sinteze temeljena je na biosintezi, čime je upotreba zaštitnih skupina svedena na minimum, a time je znatno olakšana i skraćena sinteza ovih prirodnih spojeva. Najkompleksnija ciljna molekula, penifenon A (111), sintetizirana je enantioselektivno u 9 linearnih koraka s ukupnim iskorištenjem $4,2 \%$.

\subsection{7. ( \pm )-Šeflon i trimeri tokoferola}

(土)-Šeflon (115) i trimeri tokoferola $(\mathbf{1 1 6}, \mathbf{1 1 7})$ su prirodni spojevi koji u svojoj složenoj strukturi sadrže jedinstveni spiro-kromanski tip skeleta (slika 16). Takvi spojevi u biosintezi nastaju tandemnom Diels-Alderovom reakcijom između o-QM. ${ }^{81}$ Međutim, primjeri sinteza u kojoj nastaju trimeri iz QM-a vrlo su rijetki. ${ }^{82}$<smiles>COC1=C(C(C)C)[C@]2(C)Cc3c(cc(OC)c(C(C)C)c3OC)[C@@H](C2)[C@]2(CCc3cc(OC)c(C(C)C)c(OC)c3O2)C1=O</smiles>

( \pm )-šeflon

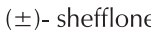

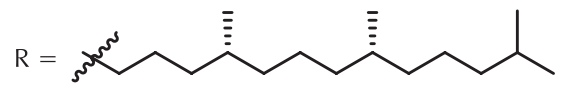

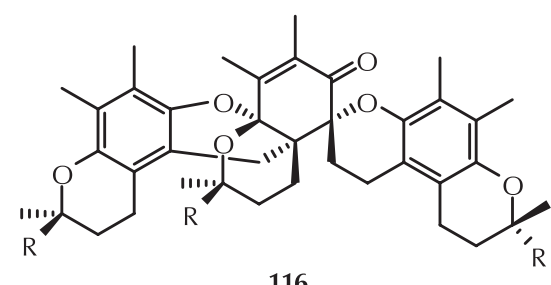

\section{6}

trimer (-)-tokoferola

(-)-tocopherol trimer

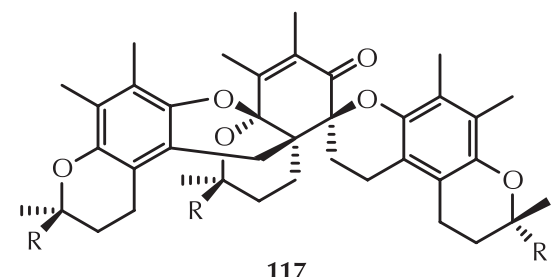

trimer (+)-tokoferola (+)-tocopherol trimer

Slika 16 - Strukture $( \pm)$-šeflona i trimera tokoferola

Fig. 16 - Structures of $( \pm)$-schefflone and tocopherol trimers 
Lei $i$ sur. razvili su vrlo jednostavnu i učinkovitu metodu sinteze takvih spojeva koja se, iz jednostavnih derivata fenola 118 kao prekursora, odvija u jednom koraku (shema 24). ${ }^{83}$ $\mathrm{Na}$ taj način uspjeli su pripraviti trimere tokoferola $116 \mathrm{i}$ 117 u dobrim iskorištenjima od $36 \%$, odnosno $37 \%$.

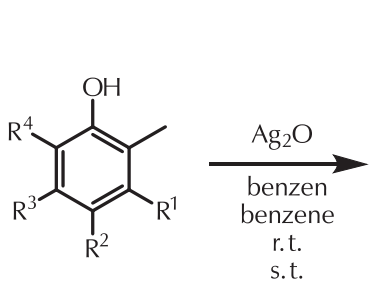

118

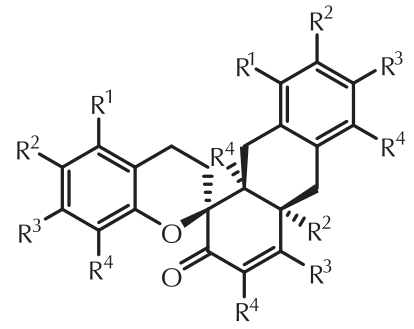

119
Shema 24 - Sinteza derivata šeflona iz jednostavnih prekursora 118

Scheme 24 - Synthesis of schefflone derivative from simple precursors 118

\subsubsection{Heliol}

Prirodni spoj heliol, koji u svojoj policikličkoj strukturi sadrži osmeročlani prsten, zahtijevao je razvoj nove metode sinteze, u kojoj se benzilni položaj fenola ponaša kao elektrofil, a pritom vezani prenilni dio služi kao intramolekulski nukleofil. Polazni spoj, fenol 120 je sintetski pripravljen. Radi se o tercijarnom alkoholu koji vrlo lako u kiselom daje dobro stabilizirani benzilni karbokation, koji nakon deprotonacije daje QM 121. Zatim dolazi do intramolekulske $[4+4]$ cikloadicije, pri čemu nastaje 3,4-benzo-srašteni 2-oksabiciklo[3.3.1]nonanski skelet koji je, kroz dodatna četiri sintetska koraka, preveden u ( \pm )-heliol (122) (shema 25). Sinteza je provedena u osam koraka s ukupnim iskorištenjem $17,6 \%{ }^{84}$

\section{Zaključak}

Kao što se može vidjeti iz ovog pregleda, QM (kinon-metidi, po IUPAC-u: kinometani) pokazuju ogroman potencijal za primjenu u organskoj sintezi. Postoje brojni načini na koje se mogu generirati iz različitih prekursora, vrlo različitim metodama i pri različitim reakcijskim uvjetima, zbog čega im je područje primjene veoma široko. Primjena ne ostaje samo na sintezi, tu su i biološki aktivni, stabilni QM, od kojih su neki izolirani iz prirodnog materijala. Nadalje, u novije vrijeme mnogo je primjera primjene QM-a u stereoselektivnim reakcijama, gdje se kiralna informacija prenosi ili s kiralnog katalizatora ili je neki od reaktanata već kiralan, te time određuje stereoselektivnost reakcije. Fenoli, njihovi derivati i spojevi sličnog skeleta često su prisutni i u strukturi prirodnih spojeva, zbog čega se upotreba QM-a u totalnoj sintezi pokazala vrlo korisnom. U konačnici, kemija QM-a je područje koje je i dalje u razvoju te u budućnosti možemo očekivati otkriće novih metoda njihovog generiranja, kao i daljnji razvoj primjene u stereoselektivnim reakcijama.

\section{Popis kratica i simbola List of abbreviations and symbols}

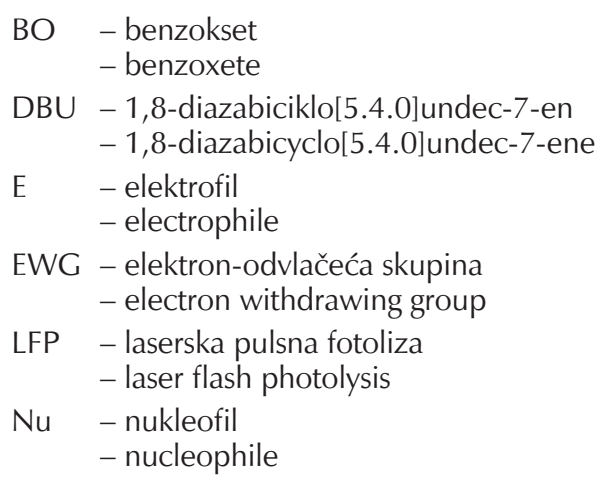<smiles>C=C(C)C(=C)CCC(C)(O)c1ccc(C)cc1O</smiles>

Shema 25 - Sinteza heliola preko međuprodukta QM-a ${ }^{84}$

Scheme 25 - Synthesis of heliol via QM intermediate ${ }^{84}$ 
QM - kinon-metid, naziv po IUPAC-u: kinometan - quinone methide, IUPAC name: quinomethane

TBS - tert-butildimetilsilil (zaštitna skupina) - tert-butyldimethylsilyl (protecting group)

TMG - 1,1,3,3-tetrametilgvanidin - 1,1,3,3-tetramethylguanidine

$\mathrm{WHO}$ - Svjetska zdravstvena organizacija - World Health Organisation

$\lambda \quad-$ valna duljina, $\mathrm{nm}$ - wavelength, $\mathrm{nm}$

$k_{2} \quad$ - konstanta brzine reakcije drugog reda, $\mathrm{mol}^{-1} \mathrm{dm}^{3} \mathrm{~s}^{-1}$ - rate constant of a second-order reaction, $\mathrm{mol}^{-1} \mathrm{dm}^{3} \mathrm{~s}^{-1}$

\section{Literatura}

\section{References}

1. M. Lukeman, Quinone Methides, S. E. Rokita (ur.), John Wiley\&Sons, Hoboken, 2009, 1. poglavlje.

2. (a) P. Wang, Y. Song, L. Zhang, H. He, X. Zhou, Quinone Methide Derivatives: Important Intermediates to DNA Alkylating and DNA Cross-linking Actions, Curr. Med. Chem. 12 (2005) 2893-2913, doi: https://doi. org/10.2174/092986705774454724; (b) M. Freccero, Quinone Methides as Alkylating and Cross-Linking Agents, Mini Rev. Org. Chem. 1 (2004) 403-415, doi: https://doi. org/10.2174/1570193043403091.

3. (a) V. S. Li, H. Kohn, Studies on the bonding specificity for mitomycin C-DNA monoalkylation processes, J. Am. Chem. Soc. 113 (1991) 275-283, doi: https://doi.org/10.1021/ ja00001a040; (b) I. Han, D. J. Russell, H. Kohn, Studies on the mechanism of mitomycin C(1) electrophilic transformations: structure-reactivity relationships, J. Org. Chem. 57 (1992) 1799-1807, doi: https://doi.org/10.1021/jo00032a037; (c) M. Tomasz, A. Das, K. S. Tang, M. G. J. Ford, A. Minnock, S. M. Musser, M. J. Waring, The Purine 2-Amino Group as the Critical Recognition Element for Sequence-Specific Alkylation and Cross-Linking of DNA by Mitomycin C, J. Am. Chem. Soc. 120 (1998) 11581-11593, doi: https://doi. org/10.1021/ja9824019.

4. (a) B. R. J. Abdella, J. Fisher, A chemical perspective on the anthracycline antitumor antibiotics, Environ. Health Perspect. 64 (1985) 4-18; (b) G. Gaudiano, M. Frigerio, P. Bravo, T. H. Koch, Intramolecular trapping of the quinone methide from reductive cleavage of daunomycin with oxygen and nitrogen nucleophiles, J. Am. Chem. Soc. 112 (1990) 6704-6709, doi: https://doi.org/10.1021/ja00174a038; (c) G. Gaudiano, T. H. Koch, Redox chemistry of anthracycline antitumor drugs and use of captodative radicals as tools for its elucidation and control, Chem. Res. Toxicol. 4 (1991) 2-16, doi: https://doi.org/10.1021/tx00019a001.

5. J. B. Chaires, N. Dattagupta, D. M. Crothers, Studies on interaction of anthracycline antibiotics and deoxyribonucleic acid: equilibrium binding studies on interaction of daunomycin with deoxyribonucleic acid, Biochemistry 21 (1982) 3933-3940, doi: https://doi.org/10.1021/bi00260a005.

6. S. R. Angle, W. Yang, Synthesis and chemistry of a quinone methide model for anthracycline antitumor antibiotics, J. Am. Chem. Soc. 112 (1990) 4524-4528, doi: https://doi. org/10.1021/ja00167a060.

7. S. R. Angle, J. D. Rainier, C. Woytowicz, Synthesis and Chemistry of Quinone Methide Models for the Anthracycline Antitumor Antibiotics, J. Org. Chem. 62 (1997) 5884-5892, doi: https://doi.org/10.1021/jo970539o.

8. P. Wan, D. W. Broumische, C. Z. Chen, J. Cole, M. Lukeman,
M. Xu, Quinone methide intermediates in organic photochemistry, Pure Appl. Chem. 73 (2001) 529-534, doi: https://doi.org/10.1351/pac200173030529.

9. P. Wan, B. Barker, L. Diao, M. Fisher, Y. Shi, C. Yang, Quinone methides: relevant intermediates in organic chemistry, Can. J. Chem. 74 (1996) 465-475, doi: https://doi.org/10.1139/ v96-051.

10. (a) K. Ramakrishnan, J. Fisher, 7-Deoxydaunomycinone quinone methide reactivity with thiol nucleophiles, J. Med. Chem. 29 (1986) 1215-1221, doi: https://doi.org/10.1021/ jm00157a017; (b) J. L. Bolton, S. B. Turnipseed, J. A. Thompson, Influence of quinone methide reactivity on the alkylation of thiol and amino groups in proteins: studies utilizing amino acid and peptide models, Chem. Biol. Interact. 107 (1997) 185-200, doi: https://doi.org/10.1016/S00092797(97)00079-3; (c) H. M. Awad, M. G. Boersma, S. Boeren, P. J. van Bladeren, J. Vervoort, I. M. C. M. Rietjens, Quenching of quercetin quinone/quinone methides by different thiolate scavengers: stability and reversibility of conjugate formation, Chem. Res. Toxicol. 16 (2003) 822-831, doi: https://doi. org/10.1021/tx020079g.

11. (a) E. Modica, R. Zanaletti, M. Freccero, M. Mella, Alkylation of Amino Acids and Glutathione in Water by o-Quinone Methide. Reactivity and Selectivity, J. Org. Chem. 66 (2001) 41-52, doi: https://doi.org/10.1021/jo0006627; (b) S. Arumugam, J. Guo, N. E. Mbua, F. Friscourt, N. Lin, E. Nekongo, G.-J. Boons, V. V. Popik, Selective and Reversible Photochemical Derivatization of Cysteine Residues in Peptides and Proteins, Chem. Sci. 5 (2014) 1591-1598, doi: https:// doi.org/10.1039/C3SC51691A.

12. (a) M. A. Lewis, D. Graff Yoerg, J. L. Bolton, J. A. Thompson, Alkylation of 2'-deoxynucleosides and DNA by quinone methides derived from 2,6-di-tert-butyl-4-methylphenol, Chem. Res. Toxicol. 9 (1996) 1368-1374, doi: https://doi. org/10.1021/tx960115+; (b) P. Pande, J. Shearer, J. Yang, W. Greenbern, S. E. Rokita, Alkylation of Nucleic Acids by a Model Quinone Methide, J. Am. Chem. Soc. 121 (1999) 6773-6779, doi: https://doi.org/10.1021/ja990456k.

13. D. C. Thompson, K. Perera, R. London, Spontaneous hydrolysis of 4-trifluoromethylphenol to a quinone methide and subsequent protein alkylation, Chem.-Biol. Interact. 126 (2000) 1-14, doi: https://doi.org/10.1016/S00092797(99)00162-3.

14. Q. Zhuo, K. D. Turnbull, Phosphodiester Alkylation with a Quinone Methide, J. Org. Chem. 64 (1999) 2847-2851, doi: https://doi.org/10.1021/jo9823745.

15. R. W. Van De Water, T. R. R. Pettus, o-Quinone methides: intermediates underdeveloped and underutilized in organic synthesis, Tetrahedron 58 (2002) 5367-5405, doi: https:// doi.org/10.1016/S0040-4020(02)00496-9.

16. A. Sharma, I. O. Santos, P. Gaur, V. F. Ferreira, C. R. S. Garcia, D. R. da Rocha, Addition of thiols to o-quinone methide: new 2-hydroxy-3-phenylsulfanylmethyl[1,4]naphthoquinones and their activity against the human malaria parasite Plasmodium falciparum (3D7), Eur. J. Med. Chem. 59 (2013) 48-53, doi: https://doi.org/10.1016/j.ejmech.2012.10.052.

17. D. C. Thompson, K. Perera, Inhibition of mitochondrial respiration by a para-quinone methide, Biochem. Biophys. Res. Commun. 209 (1995) 6-11, doi: https://doi.org/10.1006/ bbrc.1995.1462.

18. M. Azoulay, F. Chalard, J.-P. Gesson, J.-C. Florent, C. Monnereta, 2-Nitro and 4-nitro-quinone-methides are not irreversible inhibitors of bovine beta-glucuronidase, Carbohydr. Res. 332 (2001) 151-156, doi: https://doi.org/10.1002/ chin. 200136195.

19. S.-T. Huanga, K.-N. Tinga, K.-L. Wang, Development of a long-wavelength fluorescent probe based on quinone-me- 
thide-type reaction to detect physiologically significant thiols, Anal. Chim. Acta 620 (2008) 120-126, doi: https://doi. org/10.1016/j.aca.2008.05.006.

20. T. P. Pathak, M. S. Sigman, Applications of ortho-Quinone Methide Intermediates in Catalysis and Asymmetric Synthesis, J. Org. Chem. 76 (2011) 9210-9215, doi: https://doi. org/10.1021/jo201789k.

21. N. Basarić, I. Žabčić, K. Mlinarić-Majerski, P. Wan, Photochemical Formation and Chemistry of Long-Lived Adamantylidene-Quinone Methides and 2-Adamantyl Cations, J. Org. Chem. 75 (2010) 102-116, doi: https://doi. org/10.1021/jo902004n.

22. E. E. Weinert, R. Dondi, S. Colloredo-Melz, K. N. Frankenfield, C. H. Mitchell, M. Freccero, S. E. Rokita, Substituents on Quinone Methides Strongly Modulate Formation and Stability of Their Nucleophilic Adducts, J. Am. Chem. Soc. 128 (2006) 11940-11947, doi: https://doi.org/10.1021/ja062948k.

23. (a) Y. Chaing, A. J. Kresge, Y. Zhu, Kinetics and Mechanisms of Hydration of $O$-Quinone Methides in Aqueous Solution, J. Am. Chem. Soc. 122 (2000) 9854-9855, doi: https://doi. org/10.1021/ja001557h; (b) Y. Chaing, A. J. Kresge, Y. Zhu, Flash Photolytic Generation of ortho-Quinone Methide in Aqueous Solution and Study of Its Chemistry in that Medium, J. Am. Chem. Soc. 123 (2001) 8089-8094, doi: https://doi. org/10.1021/ja010826g; (c) Y. Chaing, A. J. Kresge, Y. Zhu, Flash Photolytic Generation of $o$-Quinone $\alpha$-Phenylmethide and $o$-Quinone $\alpha$-(p-Anisyl)methide in Aqueous Solution and Investigation of Their Reactions in that Medium. Saturation of Acid-Catalyzed Hydration, J. Am. Chem. Soc. 124 (2002) 717-722, doi: https://doi.org/10.1021/ja0120375.

24. K. Fries, Liebigs Ann. Chem. 339 (1907) 350-356.

25. P. D. Gardner, R. L. Brandon, H. Sarrafizadeh, o-Quinonone methide, J. Am. Chem. Soc. 81 (1959) 5515-5155, doi: https://doi.org/10.1021/ja01529a071.

26. L. K. Dyall, S. Winstein, Nuclear magnetic resonance spectra and characterization of some quinone methides, J. Am. Chem. Soc. 94 (1972) 2196-2199, doi: https://doi. org/10.1021/ja00762a007.

27. (a) H. Amouri, J. Le Bras, Taming reactive phenol tautomers and o-quinone methides with transition metals: a structure-reactivity relationship, Acc. Chem. Res. 35 (2002) 501-510, doi: https://doi.org/10.1021/ar010105m; (b) $H$. Amouri, Y. Besace, J. L. Bras, J. Vaissermann, General Synthesis, First Crystal Structure, and Reactivity of Stable o-Quinone Methide Complexes of Cp*Ir, J. Am. Chem. Soc. 120 (1998) 6171-6172, doi: https://doi.org/10.1021/ja9802145.

28. H. Meier, Benzoxetes and benzothietes - heterocyclic analogues of benzocyclobutene, Molecules 17 (2012) 15481570, doi: https://doi.org/10.3390/molecules17021548.

29. P. T. Martone, J. M. Estevez, F. Lu, K. Ruel, M. W. Denny, C. Somerville, J. Ralph, Discovery of lignin in seaweed reveals convergent evolution of cell-wall architecture, Curr. Biol. 19 (2009) 169-175, doi: https://doi.org/10.1016/j. cub.2008.12.031.

30. A. C. Allison, R. Cacabelos, V. R. Lombardi, X. A. Alvarez, C. Vigo, Celastrol, a potent antioxidant and anti-inflammatory drug, as a possible treatment for Alzheimer's disease, Prog. Neuropsychopharmacol. Biol. Psychiatry 25 (2001) 13411357, doi: https://doi.org/10.1016/S0278-5846(01)001920 .

31. R. Kannaiyan, K. A. Manu, L. Chen, F. Li, P. Rajendran, A. Subramaniam, P. Lam, A. P. Kumar, G. Sethi, Celastrol inhibits tumor cell proliferation and promotes apoptosis through the activation of c-Jun $\mathrm{N}$-terminal kinase and suppression of PI3 K/Akt signaling pathways, Apoptosis. 16 (2011) 1028-1041, doi: https://doi.org/10.1007/s10495-011-0629-6.

32. T. Murayama, Y. Eizuru, R. Yamada, H. Sadanari, K. Matsubara, G. Rukung, F. M. Tolo, G. M. Mungai, M. Kofi-Tsekpo, An- ticytomegalovirus activity of pristimerin, a triterpenoid quinone methide isolated from Maytenus heterophylla (Eckl. \& Zeyh.), Antivir. Chem. Chemother. 18 (2007) 133-139, doi: https://doi.org/10.1177/095632020701800303.

33. J. Avilla, A. Teixidò, C. Velázquez, N. Alvarenga, E. Ferro, R. Canela, Insecticidal activity of Maytenus species (Celastraceae) nortriterpene quinone methides against codling moth, Cydia pomonella (L.) (Lepidoptera: tortricidae), J. Agr. Food Chem. 48 (2000) 88-92, doi: https://doi.org/10.1021/ jf990008w.

34. S. M. Kupchan, A. Karim, C. Marcks, Taxodione and taxodone, two novel diterpenoid quinone methide tumor inhibitors from Taxodium distichum, J. Am. Chem. Soc. 90 (1968) 5923-5924, doi: https://doi.org/10.1021/ja01023a061.

35. V. K. Bajpai, M. Na, S. C. Kang, The role of bioactive substances in controlling foodborne pathogens derived from Metasequoia glyptostroboides Miki ex Hu, Food Chem. Toxicol. 48 (2010) 1945-1949, doi: https://doi.org/10.1016/j. fct.2010.04.041

36. U. Kolak, A. Kabouche, M. Öztürk, Z. Kabouche, G. Topçu, A. Ulubelen, Antioxidant diterpenoids from the roots of Salvia barrelieri, Phytochem. Anal. 20 (2009) 320-327, doi: https://doi.org/10.1002/pca.1130.

37. N. Kusumoto, T. Ashitani, T. Murayama, K. Ogiyama, K. Takahashi, Antifungal abietane-type diterpenes from the cones of Taxodium distichum Rich, J. Chem. Ecol. 36 (2010) 13811386, doi: https://doi.org/10.3390/molecules200815084.

38. N. Kusumoto, T. Ashitani, Y. Hayasaka, T. Murayama, K. Ogiyama, K. Takahashi, Antitermitic activities of abietane-type diterpenes from Taxodium distichum cones, J. Chem. Ecol. 35 (2009) 635-642, doi: https://doi.org/10.1007/s10886009-9646-0.

39. H. B. Bodea, A. Zeeck, Structure and biosynthesis of kendomycin, a carbocyclic ansa-compound from Streptomyces, J. Chem. Soc., Perkin Trans. 1 (2000) 323-328, doi: https:// doi.org/10.1039/A908387A.

40. D. A. Bolon, o-Quinone methides. II. Trapping with production of chromans, J. Org. Chem. 35 (1970) 3666-3670, doi: https://doi.org/10.1021/jo00836a016.

41. G. G.-H. Qiao, K. Lenghaus, D. H. Solomon, A. Reisinger, I. Bytheway, C. Wentrup, 4,6-Dimethyl-o-quinone Methide and 4,6-Dimethylbenzoxete, J. Org. Chem. 63 (1998) 9806-9811, doi: https://doi.org/10.1021/jo981445x.

42. M. Yato, T. Ohwanda, K. Shudo, 4H-1,2-Benzoxazines as novel precursors of $o$-benzoquinone methide, J. Am. Chem. Soc. 112 (1990) 5341-5342, doi: https://doi.org/10.1021/ ja00157a079.

43. (a) Q. Zeng, S. E. Rokita, Tandem Quinone Methide Generation for Cross-Linking DNA, J. Org. Chem. 61 (1996) 9080-9081, doi: https://doi.org/10.1021/jo961864z; (b) S. E. Rokita, J. Yang, P. Pande, W. A. Greenberg, Quinone Methide Alkylation of Deoxycytidine, J. Org. Chem. 62 (1997) 3010-3012, doi: https://doi.org/10.1021/jo9700336; (c) W. F. Veldhuyzen, A. J. Shallop, R. A. Jones, S. E. Rokita, Thermodynamic versus Kinetic Products of DNA Alkylation as Modeled by Reaction of Deoxyadenosine, J. Am. Chem. Soc. 123 (2001) 11126-11132, doi: https://doi.org/10.1021/ ja011686d; (d) W. F. Veldhuyzen, P. Pande, S. E. Rokita, Alkylation of Nucleic Acids by a Model Quinone Methide, J. Am. Chem. Soc. 125 (2003) 14005-14013, doi: https://doi. org/10.1021/ja036943o; (e) Q. Zhou, S. E. Rokita, A general strategy for target-promoted alkylation in biological systems, Proc. Natl. Acad. Sci. U.S.A. 100 (2003) 15452-15457, doi: https://doi.org/10.1073/pnas.2533112100; (f) E. E. Weinert, K. N. Frankenfield, S. E. Rokita, Time-Dependent Evolution of Adducts Formed between Deoxynucleosides and a Model Quinone Methide, Chem. Res. Toxicol. 18 (2005) 1364 1370, doi: https://doi.org/10.1021/tx0501583; (g) H. Wang, 
M. S. Wahi, S. E. Rokita, Immortalizing a Transient Electrophile for DNA Cross-Linking, Angew. Chem., Int. Ed. 47 (2008) 1291-1293, doi: https://doi.org/10.1002/anie.200704137; (h) H. Wang, S. E. Rokita, Dynamic cross-linking is retained in duplex DNA after multiple exchange of strands, Angew. Chem., Int. Ed. 49 (2010) 5957-5960, doi: https://doi. org/10.1002/anie.201001597; (i) C. S. Rossiter, E. Modica, D. Kumar, S. E. Rokita, Few constraints limit the design of quinone methide-oligonucleotide self-adducts for directing DNA alkylation, Chem. Commun. 47 (2011) 1476-1478, doi: https://doi.org/10.1039/C0CC04583G.

44. A. Arduini, A. Bossi, A. Pochini, R. Ungaro, o-Quinone methides. 2. Stereoselectivity in cycloaddition reactions of $\mathrm{O}$-quinone methides with vinyl ethers, Tetrahedron $\mathbf{4 1}$ (1985) 3095-3103, doi: https://doi.org/10.1016/S00404020(01)96662-1.

45. P. D. Gardner, H. S. Rafsanjani, L. Rand, Reaction of Phenolic Mannich Base Methiodides and Oxides with Various Nucleophiles, J. Am. Chem. Soc. 81 (1959) 3364-3367, doi: https://doi.org/10.1021/ja01522a052.

46. S. R. Angle, W. Yang, $\mathrm{pH}$-Dependent stability and reactivity of a thiol-quinone methide adduct, Tetrahedron Lett. 33 (1992) 6089-6092, doi: https://doi.org/10.1016/S00404039(00)60013-8.

47. (a) O. Bilgic, D. W. Young, A general and practicable synthesis of polycyclic heteroaromatic compounds. Part 3. Extension of the synthesis to 'quinone methides' of naphthalene, phenanthrene, and benzene, J. Chem. Soc., Perkin Trans 1 (1980) 1233-1239, doi: https://doi.org/10.1039/ P19800001233; (b) J. L. Asherson, O. Bilgic, D. W. Young, A general and practicable synthesis of polycyclic heteroaromatic compounds. Part 4. A rationale for the mechanism of the synthesis, J. Chem. Soc., Perkin Trans. 1 (1981) 30413047, doi: https://doi.org/10.1039/P19810003041.

48. D. N. Nicolaides, S. G. Adamopoulos, E. J. Hatzigrigoriou, K. E. Litinas, Synthesis and study of 10-(4-methoxybenzylidene)-9(10H)-phenanthrone, a stable ortho-quinone methanide, J. Chem. Soc., Perkin Trans. 1 (1991) 31593164, doi: https://doi.org/10.1039/P19910003159.

49. E. Breuer, D. Melumad, The reaction of o-quinone methides with dimethyl sulfoxonium methylide. A simple synthesis of coumarans, Tetrahedron Lett. 10 (1969) 1975-1877, doi: https://doi.org/10.1016/S0040-4039(01)88062-X.

50. V. A. Osyanin, D. V. Osipov, Y. N. Klimochkin, Reactions of o-Quinone Methides with Pyridinium Methylides: A Diastereoselective Synthesis of 1,2-Dihydronaphtho[2,1-b]furans and 2,3-Dihydrobenzofurans, J. Org. Chem. 78 (2013) 5505-5520, doi: https://doi.org/10.1021/jo400621r

51. M. Pisova, M. Soucek, Intermolecular cyclization of o-fuchsones, Collect. Czech. Chem. Commun. 47 (1982) 838-842, doi: https://doi.org/10.1135/cccc19820838.

52. (a) C. Selenski, T. R. R. Pettus, Enantioselective [4 + 2] Cycloadditions of $O$-Quinone Methides: Total Synthesis of $(+)$-Mimosifoliol and Formal Synthesis of $(+)$-Tolterodine J. Org. Chem. 69 (2004) 9196-9203, doi: https://doi. org/10.1021/jo048703c; (b) D. W. R. W. Van, D. J. Magdziak, J. N. Chau, T. T. R. Pettus, New Construction of Ortho Ring-Alkylated Phenols via Generation and Reaction of Assorted $O$-Quinone Methides, J. Am. Chem. Soc. 122 (2000) 6502-6503, doi: https://doi.org/10.1021/ja994209s; (c) R. M. Jones, C. Selenski, T. R. R. Pettus, Rapid Syntheses of Benzopyrans from o-OBOC Salicylaldehydes and Salicyl alcohols: A Three-Component Reaction, J. Org. Chem. 67 (2002) 6911-6915, doi: https://doi.org/10.1021/jo020224v.

53. S. Cao, R. Christiansen, X. Peng, Substituent Effects on Oxidation-Induced Formation of Quinone Methides from Arylboronic Ester Precursors, Chem. Eur. J. 19 (2013) 9050-9058, doi: https://doi.org/10.1002/chem.201300539.
54. (a) A. C. Ayers and J. K. Loike, Lignans: Chemical, Biological and Clinical Properties, Cambridge, 1990., University press, Great Britain; (b) B. M. Trost, O. R. Thiel, H.-C. Tsui, Total Syntheses of Furaquinocin A, B, and E, J. Am. Chem. Soc. 125 (2003) 13155-13164, doi: https://doi. org/10.1021/ja0364118; (c) F. Bertolini, M. Pineschi, Recent Progress in the synthesis of 2,3-dihydrobenzofurans, Org. Prep. Proced. Int. 41 (2009) 385-418, doi: https:// doi.org/10.1080/00304940903240836; (d) E. D. Coy, L. Jovanovic, M. Sefkow, One-Pot, Pd-Catalyzed Synthesis of trans-Dihydrobenzofurans from o-Aminophenols, Org. Lett. 12 (2010) 1976-1979, doi: https://doi.org/10.1021/ ol100433z; (e) F. Baragona, T. Lomberget, C. Duchamp, N. Henriques, E. L. Piccolo, P. Diana, A. Montalbano, R. Barret, Synthesis of 5-substituted 2,3-dihydrobenzofurans in a onepot oxidation/cyclization reaction, Tetrahedron 67 (2011) 8731-8739, doi: https://doi.org/10.1016/j.tet.2011.09.020; (f) S. Malik, U. K. Nadir, P. S. Pandey, Reactions of 2-hydroxyaryl- $\alpha, \beta$-unsaturated ketones with dimethylsulfonium carbonylmethylides: a new and facile diastereoselective synthesis of 2,3-disubstituted dihydrobenzofurans, Tetrahedron 65 (2009) 3918-3924, doi: https://doi.org/10.1016/j. tet.2009.02.041; (g) B. Vinosha, S. Perumal, S. Renuga, A. I. Almansour, A facile domino protocol for the stereoselective synthesis of trans-2,3-dihydrobenzofurans and cis-5,6-dihydrofuro[2,3-d]pyrimidines, Tetrahedron Lett. 53 (2012) 962-966, doi: https://doi.org/10.1016/j.tetlet.2011.12.047.

55. M.-W. Chen, L.-L. Cao, Z.-S. Ye, G.-F. Jiang, Y.-G. Zhou, A mild method for generation of $O$-quinone methides under basic conditions. The facile synthesis of trans-2,3-dihydrobenzofurans, Chem. Commun. 49 (2013) 1660-1662, doi: https:// doi.org/10.1039/C3CC37800D.

56. (a) T. N. Pattabiraman, W. B. Lawson, Stereochemistry of the active site of $\alpha$-chymotrypsin. The effect of some tricyclic bromomethyl ketones on $\alpha$-chymotrypsin, Biochem. Biophys. Acta 258 (1972) 548-553, doi: https://doi. org/10.1016/0005-2744(72)90246-X; (b) J. L. Adams, R. S. Garigipati, M. Sorenson, S. J. Schmidt, W. R. Brian, J. F. Newton, K. A. Tyrrell, E. Garver, L. A. Yodis, M. Chabot-Fletcher, M. Tzimas, E. F. Webb, J. J. Breton, D. E. Griswold, Bicyclic $\mathrm{N}$-hydroxyurea inhibitors of 5-lipoxygenase: pharmacodynamic, pharmacokinetic, and in vitro metabolic studies characterizing N-hydroxy-N-(2,3-dihydro-6-(phenylmethoxy)-3-benzofuranyl)urea, J. Med. Chem. 39 (1996) 50355046, doi: https://doi.org/10.1021/jm960271d; (c) N. Matsunaga, T. Kaku, A. Ojida, T. Tanaka, T. Hara, M. Yamaoka, M. Kusaka, A. Tasaka, C17,20-lyase inhibitors. Part 2: Design, synthesis and structure-activity relationships of (2-naphthylmethyl)-1H-imidazoles as novel C17,20-lyase inhibitors, Bioorg. Med. Chem. 12 (2004) 4313-4336, doi: https://doi. org/10.1016/j.bmc.2004.06.016.

57. A. Goel, A. Kumar, A. Raghuvanshi, Synthesis, stereochemistry, structural classification, and chemical reactivity of natural pterocarpans, Chem. Rev. 113 (2013) 1614-1640, doi: https://doi.org/10.1021/cr300219y.

58. L.-M. Zhao, A.-L. Zhang, H.-S. Gao, J.-H. Zhang, Synthesis of Furo[3,2-c]benzopyrans via an Intramolecular $[4+2]$ Cy-

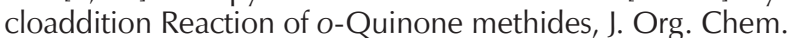
80 (2015) 10353-10358, doi: https://doi.org/10.1021/acs. joc. 5 b01641.

59. (a) D. L. Boger, D. S. Johnson, CC-1065 and the duocarmycins: unraveling the keys to a new class of naturally derived DNA alkylating agents, Proc. Natl. Acad. Sci. USA 92 (1995) 3642-3649, doi: https://doi.org/10.1073/pnas.92.9.3642; (b) M. A. Warpehoski, D. E. Harper, Acid-Dependent Electrophilicity of Cyclopropylpyrroloindoles. Nature's Masking Strategy for a Potent DNA Alkylator, J. Am. Chem. Soc. 116 (1994) 7573-7580, doi: https://doi.org/10.1021/ ja00096a014; (c) D. L. Boger, B. Bollinger, D. L. Hertzog, D. 
S. Johnson, H. Cai, P. Mésini, R. M. Garbaccio, Q. Jin, P. A. Kitos, Reversed and Sandwiched Analogs of Duocarmycin SA: Establishment of the Origin of the Sequence-Selective Alkylation of DNA and New Insights into the Source of Catalysis, J. Am. Chem. Soc. 119 (1997) 4987-4998, doi: https:// doi.org/10.1021/ja9637210; (d) D. L. Boger, A. Santillán Jr., M. Searcey, Q. Jin, Critical Role of the Linking Amide in CC1065 and the Duocarmycins: Implications on the Source of DNA Alkylation Catalysis, J. Am. Chem. Soc. 120 (1998) 11554-11557, doi: https://doi.org/10.1021/ja9818093.

60. M. Hassam, A. E. Basson, D. C. Liotta, L. Morris, W. A. L. van Otterlo, S. C. Pelly, Novel Cyclopropyl-Indole Derivatives as HIV Non-Nucleoside Reverse Transcriptase Inhibitors, ACS Med. Chem. Lett. 3 (2012) 470-475, doi: https://doi. org/10.1021/ml3000462.

61. A. Ouyang, E. B. Skibo, Design of a Cyclopropyl Quinone Methide Reductive Alkylating Agent, J. Org. Chem. 63 (1998) 1893-1900, doi: https://doi.org/10.1021/jo971808d.

62. (a) W. A. Remers, u The Chemistry of Antitumor Antibiotics Vol. 1; John Wiley \& Sons Inc., New York, 1979, str. 221276; (b) R. W. Franck, M. Tomasz, u D. E. Wilman (ur.), The Chemistry of Antitumor Agents, Blackie \& Sons: Ltd.: Glasgow, Škotska, 1990; str. 379-394; (c) R. C. Boruah, E. B. Skibo, Determination of the $\mathrm{p} K_{\mathrm{a}}$ Values for the Mitomycin C Redox Couple by Titration, $\mathrm{pH}$ Rate Profiles, and NernstClark Fits. Studies of Methanol Elimination, Carbocation Formation, and the Carbocation/Quinone Methide Equilibrium, J. Org. Chem. 60 (1995) 2232-2243, doi: https://doi. org/10.1021/jo00112a051.

63. (a) B. T. Ramanjaneyulu, S. Mahesh, R. V. Anand, Bis(amino) cyclopropenylidene-Catalyzed 1,6-Conjugate Addition of Aromatic Aldehydes to para-Quinone Methides: Expedient Access to $\alpha, \alpha^{\prime}$-Diarylated Ketones, Org. Lett. 17 (2015) 39523955, doi: https://doi.org/10.1021/acs.orglett.5b01724; (b) V. Reddy, R. V. Anand, Expedient Access to Unsymmetrical Diarylindolylmethanes through Palladium-Catalyzed Domino Electrophilic Cyclization-Extended Conjugate Addition Approach, Org. Lett. 17 (2015) 3390-3393, doi: https:// doi.org/10.1021/acs.orglett.5b01030; (c) A. López, A. Parra, C. Jarava-Barrera, M. Tortosa, Copper-catalyzed silylation of $p$-quinone methides: new entry to dibenzylic silanes, Chem. Commun. 51 (2015) 17684-17687, doi: https://doi. org/10.1039/c5cc06653k; (d) W.-D. Chu, L.-F. Zhang, X. Bao, X.-H. Zhao, C. Zeng, J.-Y. Du, G.-B. Zhang, F.-X. Wang, X.-Y. Ma, C.-A. Fan, Asymmetric catalytic 1,6-conjugate addition/ aromatization of para-quinone methides: enantioselective introduction of functionalized diarylmethine stereogenic centers, Angew. Chem., Int. Ed. 52 (2013) 9229-9233, doi: https://doi.org/10.1002/anie.201303928; (e) L. Caruana, F. Kniep, T. K. Johansen, P. H. Poulsen, K. A. Jorgensen, A new organocatalytic concept for asymmetric $\alpha$-alkylation of aldehydes, J. Am. Chem. Soc. 136 (2014) 15929-15933, doi: https://doi.org/10.1021/ja510475n; (f) Y. Lou, P. Cao, T. Jia, Y. Zhang, M. Wang, J. Liao, Copper-catalyzed enantioselective 1,6-boration of para-quinone methides and efficient transformation of gem-diarylmethine boronates to triarylmethanes, Angew. Chem., Int. Ed. 54 (2015) 12134 12138, doi: https://doi.org/10.1002/anie.201505926; (g) Z. Wang, Y. F. Wong, J. Sun, Catalytic Asymmetric 1,6-Conjugate Addition of para-Quinone Methides: Formation of All-Carbon Quaternary Stereocenters, Angew. Chem., Int. Ed. 54 (2015) 13711-13714, doi: https://doi.org/10.1002/ anie.201506701; (h) N. Dong, Z.-P. Zhang, X.-S. Xue, X. Li, J.$P$. Cheng, Phosphoric Acid Catalyzed Asymmetric 1,6-Conjugate Addition of Thioacetic Acid to para-Quinone Methides, Angew. Chem., Int. Ed. 55 (2016) 1460-1464, doi: https:// doi.org/10.1002/anie.201509110; (i) C. Jarava-Barrera, A. Parra, A. López, F. Cruz-Acosta, D. Collado-Sanz, D. J. Cárdenas, M. Tortosa, Copper-Catalyzed Borylative Aromatiza- tion of $p$-Quinone Methides: Enantioselective Synthesis of Dibenzylic Boronates, ACS Catal. 6 (2016) 442-446, doi: https://doi.org/10.1021/acscatal.5b02742; (j) K. Zhao, Y. Zhi, A. Wang, D. Enders, Asymmetric Organocatalytic Synthesis of 3-Diarylmethine-Substituted Oxindoles Bearing a Quaternary Stereocenter via 1,6-Conjugate Addition to para-Quinone Methides, ACS Catal. 6 (2016) 657-660, doi: https:// doi.org/10.1021/acscatal.5b02519; (k) F.-S. He, J.-H. Jin, Z.-T. Yang, X. Yu, J. S. Fossey, W.-P. Deng, Direct Asymmetric Synthesis of $\beta$-Bis-Aryl- $\alpha$-Amino Acid Esters via Enantioselective Copper-Catalyzed Addition of $p$-Quinone Methides, ACS Catal. 6 (2016) 652-656, doi: https://doi.org/10.1021/acscatal.5b02619; (I) X. Li, X. Xu, W. Wei, A. Lin, H. Yao, Organocatalyzed Asymmetric 1,6-Conjugate Addition of para-Quinone Methides with Dicyanoolefins, Org. Lett. 18 (2016) 428-431, doi: https://doi.org/10.1021/acs.orglett.5b03471.

64. W. Baik, H. J. Lee, J. M. Jang, S. Koo, B. H. Kim, NBS-Promoted reactions of symmetrically hindered methylphenols via p-benzoquinone methide, J. Org. Chem. 65 (2000) 108115, doi: https://doi.org/10.1021/jo9911185.

65. S. Kim, Y. Kitano, M. Tada, K. Chiba, Alkylindan synthesis via an intermolecular [3+2] cycloaddition between unactivated alkenes and in situ generated $p$-quinomethanes, Tetrahedron Lett. 41 (2000) 7079-7083, doi: https://doi.org/10.1016/ S0040-4039(00)01216-8.

66. X.-Z. Zhang, J.-Y. Du, Y.-H. Deng, W.-D. Chu, X. Yan, K.-Y. Yu, C.-A. Fan, Spirocyclopropanation Reaction of para-Quinone Methides with Sulfonium Salts: The Synthesis of Spirocyclopropanyl para-Dienones, J. Org. Chem. 81 (2016) 25982606, doi: https://doi.org/10.1021/acs.joc.5b02725.

67. (a) R. A. Edrada,; C. C. Stessman,; P. J. Crews, Uniquely modified imidazole alkaloids from a calcareous Leucetta sponge, Nat. Prod. 66 (2003) 939-942, doi: https://doi.org/10.1021/ np020503d; (b) H. Sorek, A. Rudi, I. Goldberg, M. Aknin, Y. Kashman, Saldedines A and B, dibromo proaporphine alkaloids from a Madagascan tunicate, J. Nat. Prod. 72 (2009) 784-786, doi: https://doi.org/10.1021/np800714k; (c) H. B. Park, Y.-J. Kim, J. K. Lee, K. R. Lee, H. C. Kwon, Spirobacillenes $A$ and $B$, unusual spiro-cyclopentenones from Lysinibacillus fusiformis KMC003, Org. Lett. 14 (2012) 5002-5005, doi: https://doi.org/10.1021/ol302115z.

68. Z. Yuan, W. Wei, A. Lin, H. Yao, Bifunctional Organo/Metal Cooperatively Catalyzed [3 + 2] Annulation of para-Quinone Methides with Vinylcyclopropanes: Approach to Spiro[4.5] deca-6,9-diene-8-ones, Org. Lett. 18 (2016) 3370-3373, doi: https://doi.org/10.1021/acs.orglett.6b01512.

69. L. W. Schenck, K. Kuna, W. Frank, A. Albert, C. Aschea, U. Kucklaender, 1,4,9,10-Anthradiquinone as precursor for antitumor compounds, Bioorganic \& Medicinal Chemistry 14 (2006) 3599-3614, doi: https://doi.org/10.1016/j. bmc.2006.01.026.

70. K. Tangdenpaisal, W. Phakhodee, S. Ruchirawat, P. Ploypradith, Facile synthesis of diarylmethanes via quinone methides, Tetrahedron 69 (2013) 933-941, doi: https://doi. org/10.1016/j.tet.2012.10.087.

71. K. Yeung, H. Kim, H. Mohapatra, S. T. Phillips, Surface-Accessible Detection Units in Self-Immolative Polymers Enable Translation of Selective Molecular Detection Events into Amplified Responses in Macroscopic, Solid-State Plastics, J. Am. Chem. Soc. 137 (2015) 5324-5327, doi: https://doi. org/10.1021/jacs.5b02799.

72. International Program of Chemical Safety, Environmental health criteria 227 (Fluoride), Svjetska zdravstvena organizacija (WHO), Ženeva, 2002., str. 100.

73. C. Selenski, L. Mejorado, T. R. R. Pettus, Diastereoselective [4+2] Reactions of $O$-Quinone Methides with a Chiral Enol Ether: Asymmetric Synthesis of (+)-R-Mimosifoliol, Synlett, (2004) 1101-1103, doi: https://doi. 
org/10.1055/s-2004-822888.

74. J. P. Lumb, D. Trauner, Pericyclic reactions of prenylated naphthoquinones: biomimetic syntheses of mollugin and microphyllaquinone, Org. Lett. 7 (2005) 5865-5868, doi: https://doi.org/10.1021/ol052472u.

75. R. Singh, Geetanjali, S. M. S. Chauhan, 9,10-Anthraquinones and other biologically active compounds from the genus Rubia, Chem. Biodivers. 1 (2004) 1241-1264, doi: https://doi. org/10.1002/cbdv.200490088.

76. (a) S. Subeki, S. Nomura, H. Matsuura, M. Yamasaki, O. Yamato, Y. Maede, K. Katakura, M Suzuki, T. Chairul, T. Yoshihara, Anti-Babesial Activity of Some Central Kalimantan Plant Extracts and Active Oligostilbenoids from Shorea balangeran, Planta Med. 71 (2005) 420-423, doi: https://doi. org/10.1055/s-2005-864136; (b) H. Matsuda, Y. Asao, S. Nakamura, M. Hamao, S. Sugimoto, M. Hongo, Y. Pongpiriyadacha, M. Yoshikawa, Antidiabetogenic constituents from the Thai traditional medicine Cotylelobium melanoxylon, Chem. Pharm. Bull. 57 (2009) 487-494, doi: https://doi. org/10.1248/cpb.57.487.

77. O. O. Fadeyi, R. N. Daniels, S. M. DeGuire, C. W. Lindsley, Total synthesis of polemannones B and C Tetrahedron Lett. 50 (2009) 3084-3087, doi: https://doi.org/10.1016/j.tetlet.2009.04.043.

78. A. A. Stierle, D. B. Stierle, K. Kelly, Berkelic acid, a novel spiroketal with selective anticancer activity from an acid mine waste fungal extremophile, J. Org. Chem. 71 (2006) 5357-5360, doi: https://doi.org/10.1021/jo060018d.

79. T. A. Wenderski, M. A. Marsini, T. R. R. Pettus, A Diastereoselective Formal Synthesis of Berkelic Acid, Org. Lett. 13 (2011) 118-121, doi: https://doi.org/10.1021/ol102652t.

80. J. T. J. Spence, J. H. George, Total Synthesis of Peniphenones
A-D via Biomimetic Reactions of a Common o-Quinone Methide Intermediate, Org. Lett. 17 (2015) 5970-5973, doi: https://doi.org/10.1021/acs.orglett.5b02902.

81. (a) R. F. Moore, W. A. Waters, Some products formed from phenolic inhibitors during the autoxidation of cumene, J. Chem. Soc. (1954) 243-246; (b) D. A. Bolon, Generation of $\mathrm{O}$-quinone methides in solution. Trimerization, J. Org. Chem. 35 (1970) 715-719, doi: https://doi.org/10.1021/ jo00828a038.

82. (a) E. S. Krol, D. D. J. Escalante, D. C. Liebler, Mechanisms of dimer and trimer formation from ultraviolet-irradiated $\alpha$-tocopherol, Lipids 36 (2001) 49-55, doi: https://doi. org/10.1007/s11745-001-0667-y; (b) H. Schröder, T. Netscher, Determination of the absolute stereochemistry of vitamin E derived oxa-spiro compounds by NMR spectroscopy, Magn. Reson. Chem. 39 (2001) 701-708, doi: https://doi. org/10.1002/mrc.927; (c) R. Yamauchi, K. Kato, Y. Ueno, Formation of trimers of $\alpha$-tocopherol and its model compound, 2,2,5,7,8-pentamethylchroman-6-ol, in autoxidizing methyl linoleate, Lipids 23 (1988) 779-783, doi: https://doi. org/10.1007/BF02536221; (d) D. R. Nelan, C. D. Robeson, The Oxidation Product from $\alpha$-Tocopherol and Potassium Ferricyanide and Its Reaction with Ascorbic and Hydrochloric Acids, J. Am. Chem. Soc. 84 (1962) 2963-2965, doi: https://doi.org/10.1021/ja00874a025.

83. D. Liao, H. Li, X. Lei, Efficient Generation of ortho-Quinone Methide: Application to the Biomimetic Syntheses of ( \pm )-Schefflone and Tocopherol Trimers, Org. Lett. 14 (2012) 18-21, doi: https://doi.org/10.1021/ol202641y.

84. J. C. Green, E. R. Brown, T. R. R. Pettus, Intramolecular Condensation via an $o$-Quinone Methide: Total Synthesis of (士)-Heliol, Org. Lett. 14 (2012) 2929-2931, doi: https://doi. org/10.1021/ol301092w.

\section{SUMMARY}

\section{Quinone Methides (Part I): Reactive Intermediates in the Chemistry of Phenols and Their Application in Organic Synthesis \\ Đani Škalamera, ${ }^{*}$ Tatjana Šumanovac Ramljak, and Antonija Husak}

Quinone methides (QMs, IUPAC name: quinomethanes) are reactive intermediates which are very important in organic chemistry. Their applications in organic synthesis are widely recognized, which has led to the development of a large number of methods for their generation. They are useful in stereoselective reactions, which open them the way for applications in total synthesis, often for structures that have already shown significant biological activity. This review gives an insight into the methods of synthetic (thermal) generation of QMs and their applications in organic synthesis, with an emphasis on the biological activity of QMs or the products obtained from them in the synthesis.

\section{Keywords}

Quinone methides, phenol derivatives, thermal generation of quinone methides, quinone methides in organic synthesis, antiproliferative activity

Ruđer Bošković Institute

Bijenička cesta 54

10000 Zagreb
Review

Received July 21, 2016 Accepted August 28, 2016 